\title{
Proteome mapping of epidermal growth factor induced hepatocellular carcinomas identifies novel cell metabolism targets and mitogen activated protein kinase signalling events
}

Jürgen Borlak, Prashant Singh and Giuseppe Gazzana

\begin{abstract}
Background: Hepatocellular carcinoma (HCC) is on the rise and the sixth most common cancer worldwide. To combat HCC effectively research is directed towards its early detection and the development of targeted therapies. Given the fact that epidermal growth factor (EGF) is an important mitogen for hepatocytes we searched for disease regulated proteins to improve an understanding of the molecular pathogenesis of EGF induced HCC. Disease regulated proteins were studied by 2DE MALDI-TOF/TOF and a transcriptomic approach, by immunohistochemistry and advanced bioinformatics.
\end{abstract}

Results: Mapping of EGF induced liver cancer in a transgenic mouse model identified $n=96(p<0.05)$ significantly regulated proteins of which $n=54$ were tumour-specific. To unravel molecular circuits linked to aberrant EGFR signalling diverse computational approaches were employed and this defined $n=7$ key nodes using $n=82$ disease regulated proteins for network construction. STRING analysis revealed protein-protein interactions of > $70 \%$ disease regulated proteins with individual proteins being validated by immunohistochemistry. The disease regulated network proteins were mapped to distinct pathways and bioinformatics provided novel insight into molecular circuits associated with significant changes in either glycolysis and gluconeogenesis, argine and proline metabolism, protein processing in endoplasmic reticulum, Hif- and MAPK signalling, lipoprotein metabolism, platelet activation and hemostatic control as a result of aberrant EGF signalling. The biological significance of the findings was corroborated with gene expression data derived from tumour tissues to evntually define a rationale by which tumours embark on intriguing changes in metabolism that is of utility for an understanding of tumour growth. Moreover, among the EGF tumour specific proteins $n=11$ were likewise uniquely expressed in human HCC and for $n=49$ proteins regulation in human HCC was confirmed using the publically available Human Protein Atlas depository, therefore demonstrating clinical significance.

Conclusion: Novel insight into the molecular pathogenesis of EGF induced liver cancer was obtained and among the 37 newly identified proteins several are likely candidates for the development of molecularly targeted therapies and include the nucleoside diphosphate kinase A, bifunctional ATP-dependent dihydroyacetone kinase and phosphatidylethanolamine-binding protein1, the latter being an inhibitor of the Raf-1 kinase.

Keywords: Epidermal growth factor, Transgenic mice, Hepatocellular carcinoma, 2D-PAGE, MALDI-TOF/TOF, Immunhistochemistry, Computational biology

\footnotetext{
* Correspondence: Borlak.Juergen@mh-hannover.de

Centre for Pharmacology and Toxicology, Hannover Medical School,

Carl-Neuberg-Str. 1, 30625 Hannover, Germany
} 


\section{Background}

Liver malignancies are common cancers worldwide and are responsible for approximately one million deaths each year with most HCC patients having poor prognosis as a result of rapid disease progression. The relative 5 -year survival rate is about $15 \%$ and can be attributed to an advanced stage of disease at the time of diagnosis, the occurrence of cirrhosis and of other co-morbidites [1]. Detection of early stages of disease is essential for an improved prognosis and overall survival. However, apart from alpha-fetoprotein (AFP) only a few serological markers are available in clinical practice (such as Glypican-3, miR-21, fucosylated GP73, $\alpha$-fucosidase) with AFP diagnostics remaining unsatisfactory because of its low sensitivity and the non-specific correlation between the clinical behavior of HCC and AFP blood levels. For this reason, new biomarkers are in strong demand $[2,3]$ and more selective markers, such as soluble interleukin-2 receptor levels, are evaluated [4].

Importantly, research into the molecular pathogenesis of HCC identified several signalling pathways as deregulated. This inspired the development of molecularly targeted therapies such as the multikinase inhibitor sorafenib that inhibits signalling of C-RAF-1, MEK, ERK, VEGFR, PDGFR and other kinases, effectively [5]. Given that epidermal growth factor is an important mitogen for hepatocytes we were particularly interested in an understanding of the consequences of its targeted overexpression in liver. In our initial study we reported the oncogenomics and pathology of EGF induced hepatocarcinogenesis and an identification of molecular circuitries linked to exaggerated EGFR signalling [6]. Furthermore, we investigated the serum proteome of EGF-tumourbearing mice to obtain information on disease-regulated proteins and to search for novel biomarkers at different stages of disease [7]. Note, a regulatory loop was proposed whereby EGF induces transcriptional activation of HDAC2 by CK2A/AKT activation in liver cancer cells [8]. Additionally, inhibition of EGFR in different animal models by Erlotinib was shown to attenuate liver fibrosis and the development of hepatocellular carcinoma [9] thus suggesting new therapeutic intervention strategies in the prevention of HCC. Indeed, the EGF receptor tyrosin kinase plays a much wider role in the immortalization of different cell types as originally anticipated [10], and is highly expressed in a number of solid tumours and EGFR over-expression correlates well with tumour progression, resistance to chemotherapy and poor prognosis.

The present study aimed at an identification of disease regulated proteins to facilitate an improved understanding of its complex signalling networks and to search for cross-talk amongst other pathways while an identification of disease regulated proteins would aid the development of molecularly targeted therapies.
For this purpose, a two-dimensional electrophoresis (2-DE) and MALDI-TOF/TOF MS strategy was employed to identify disease regulated proteins in an EGF transgenic mouse model of HCC. This resulted in an identification of 96 statistically significant regulated proteins of which 54 are uniquely expressed in liver cancer. Importantly, 11 out of 54 mouse tumour specific proteins were likewise uniquely expressed in human $\mathrm{HCC}$ and 49 disease regulated proteins identified in EGF induced liver cancer were similarly regulated in human HCC, as determined by immunhistochemistry using different antibodies and the information given in the publically available Human Protein Atlas depository. Clinical significance of the identified proteins could be demonstrated and a total of 37 so far unkown proteins could now be related to EGF induced liver cancer, several of which are likely candidates for the development of molecularly targeted therapies. This includes the nucleoside diphosphate kinase A, bifunctional ATP-dependent dihydroxyacetone kinase, phosphatidylethanolamine binding protein1, i.e. an inhibitor of the RAF-1 kinase as well as aldo-keto reductase family 1 proteins, members $\mathrm{C} 14$ and $\mathrm{C} 6$, interleukin 25 and the v-crk sarcoma virus CT10 oncogene homolog.

Finally, to gain insight into the molecular circuitries of EGFR induced hepatocarcinogenesis diverse computational approaches were employed. This revealed master regulatory proteins and permitted network constructions of 82 disease regulated proteins with protein-protein interactions being confirmed for $>70 \%$ of regulated proteins in STRING analysis. Their regulations were also studied by immunohistochemistry in EGF transgenic HCC.

We also compared the serum and liver proteomes of HCC bearing mice and found 10 proteins to be similarly regulated, thus evidencing leakage of tumour proteins that can be detected in serum. Obviously, these are highly interesting biomarker candidates, 6 of which were also regulated in human $\mathrm{HCC}$ as determined by immunohistochemistry.

\section{Methods}

\section{Animal studies}

All animal work followed strictly the Public Health Service (PHS) Policy on Humane Care and Use of Laboratory Animals of the National Institutes of Health, USA. Formal approval to carry out animal studies was granted by the animal welfare ethics committee of the State of Lower Saxony, Germany ('Lower Saxony State Office for Consumer Protection and Food Safety' (LAVES)). The approval ID is Az: 33.9-42502-04-06/1204.

A total of $n=12$ C57/Bl6 non-transgenic and $n=12 \mathrm{EGF}$ transgenic mice (aged 6-8 months), weighing 25-33 g, were housed in Makrolon ${ }^{\circ}$ Type III cages. Water and food (V1124-000, SSNIFF, The Netherlands) was given ad libitum. The temperature and relative humidity was set to $22 \pm 2^{\circ} \mathrm{C}$ and $40-70 \%$, respectively and a 12 -h day and night cycle was used. 


\section{Materials and reagents}

Tris, urea, thiourea, CHAPS, dithiothreitol, bromophenol blue, glycerin, sodium dodecyl sulfate, glycine, temed, ammoniumperoxodisulfate, ammonium sulfate, ammonium bicarbonate, colloidal Coomassie Blue, and acrylamide were purchased from Roth (Karlsruhe, Germany). Iodacetamide was obtained from SERVA (Heidelberg, Germany) and benzonase was purchased from Novagen (Darmstadt, Germany). Ampholytes (Biolyte 3-10) were purchased from Bio-Rad Laboratories (München, Germany) and DeStreak was obtained from Amersham Bioscience (Freiburg, Germany).

\section{Mouse liver sample preparation}

Mice were anesthetized with ketamine $10 \% 100 \mu \mathrm{L} / 100 \mathrm{~g}$ and xylazine $2 \% 50 \mu \mathrm{L} / 100 \mathrm{~g}$, and after surgical removal the liver was perfused and rinsed with ice cold Ringer solution until free of blood.

Approximately $0.1 \mathrm{~g}$ of the liver sample was ground in a mortar under liquid nitrogen flow. Then, the samples were processed with $0.5 \mathrm{~mL}$ of a buffer containing $40 \mathrm{mM}$ tris base, $7 \mathrm{M}$ urea, 4\% CHAPS, $100 \mathrm{mM}$ DTT, and $0.5 \%(\mathrm{v} / \mathrm{v})$ biolyte $3-10$ first (LB2). The suspensions were homogenized by sonication $(3 \times 20 \mathrm{~s})$ and after addition of $3 \mu \mathrm{L}$ of benzonase (endonuclease that degrades DNA and RNA) were left at room temperature for $20 \mathrm{~min}$. The samples were then centrifuged at $12,000 \mathrm{~g}$ for $20 \mathrm{~min}$. The pellets were washed and sonicated for $5 \mathrm{~min}$ with a further $0.5 \mathrm{~mL}$ of LB2 and centrifuged at 12,000 $\mathrm{g}$ for another $20 \mathrm{~min}$, and the resulting two fractions of supernatant were collected (extract A). Finally, the pellets were redissolved with $0.5 \mathrm{~mL}$ of buffer containing $40 \mathrm{mM}$ tris base, $5 \mathrm{M}$ urea, $2 \mathrm{M}$ thiourea, 4\% CHAPS, $100 \mathrm{mM}$ DTT, and 0.5\% (v/v) biolyte 3-10 (LB3), sonicated, and centrifuged at 12,000 g for $20 \mathrm{~min}$. The pellet was collected, and the supernatant was marked as extract $B$.

From the same animals, a further $0.1-\mathrm{g}$ portion was ground in a mortar, but was now treated with $0.5 \mathrm{~mL}$ of LB3. The suspensions were sonicated, incubated with benzonase, and centrifuged. The pellets were then washed with another $0.5 \mathrm{~mL}$ of LB3, sonicated and centrifuged, and the supernatants were collected (extract C).

Proteome mapping was done under a variety of conditions, e.g. extraction with lysis buffers 2 and 3 . In addition, proteins were separated at two different $\mathrm{pH}$ ranges [5-10]. A total of 4 independent experiments were carried out, and duplicate measurements were run for each experiment. The protein concentration of all extracts was determined using the Bradford assay.

\section{Liquid-phase IEF pre-fractionation}

Liquid-phase IEF pre-fractionation was performed in the Rotofor Cell system (Bio-Rad) following the supplier's instructions. Ion exchange membranes were equilibrated overnight in the appropriate electrolyte (anion exchange membranes in $\mathrm{NaOH} 0.1 \mathrm{M}$ and cation exchange membranes in $\mathrm{H}_{3} \mathrm{PO}_{4} 0.1 \mathrm{M}$ ). After four runs ion exchange membranes were always discarded and new membranes were replaced for the other samples. For each run, the electrode chambers were filled with appropriate fresh electrolytes $(30 \mathrm{~mL})$. Initially, the cell was filled with pure water and run for $5 \mathrm{~min}$ at 5 watts constant power to remove residual ionic contaminants from the membrane core and ion exchange membranes. Approximately $32 \mathrm{~mL}$ of LB2 were used to fill the cell. A total of $60 \mathrm{mg}$ of total proteins in approximately $2 \mathrm{~mL}$ of LB2 were added to the cell to reach the maximum loadable volume $(40 \mathrm{~mL})$. Focusing started at 12 watts constant power. After approximately 4 hours the voltage increased to $3000 \mathrm{~V}$ and the wattage decreased to $3 \mathrm{~W}$. The focused proteins were harvested in $20 \sim 1.5 \mathrm{~mL}$ fractions, and $\mathrm{pH}$ values were checked. Fractions having $\mathrm{pH}$ values between 3 and 7.0 were collected and denoted "A-a" (acid). Fractions having $\mathrm{pH}$ values $>7.0$ were collected and denoted "A-b" (basic). Again, the protein concentration was determined for both fractions (A-a and A-b) by the Bradford method. Approximately $30 \mathrm{mg}$ of protein were recovered at the end of the liquid-phase IEF pre-fractionation from an initial 60-mg load. The losses are accounted for by the multi-step pre-fractionation procedure, but are not the result of a precipitate that could not be dissolved in our lysis buffer. After each run the membrane core was cleaned with $\mathrm{NaOH} 0.1 \mathrm{M}$ overnight and sonicated for $5 \mathrm{~min}$ in water before the new focusing.

\section{Two-dimensional gel electrophoresis Isoelectric focusing (IEF) - first dimension}

IEF was performed using precast linear IPG strips. The 17-cm IPG strips 7-10 and 5-8 were loaded with $1.5 \mathrm{mg}$ of proteins by active rehydration ( $12 \mathrm{~h}, 50 \mathrm{~V})$. Samples destined to be separated by IPG strips 7-10 received an excess of hydroxyethyldisulphide (HED) (DeStreak ${ }^{\mathrm{TM}}$ ) prior to the focusing run. Focusing began at $250 \mathrm{~V}$ for $20 \mathrm{~min}$ in rapid mode, 10,000 $\mathrm{V}$ for $5 \mathrm{~h}$ in linear mode and 10,000 V for $50,000 \mathrm{Vh}$ in rapid mode (for the IPG strips 5-8). IEF for the strips 7-10 was carried out at $250 \mathrm{~V}$ for $60 \mathrm{~min}$ in rapid mode, 10,000 $\mathrm{V}$ for $3 \mathrm{~h}$ in linear mode and 10,000 V for 50,000 Vh in rapid mode. Each sample was analysed in duplicate. Control and HCC samples were run always at the same time (6 control and 6 HCC samples).

\section{2-DE - second dimension}

After IEF, the IPG strips were either stored at $-80^{\circ} \mathrm{C}$ or transferred to $10 \mathrm{~mL}$ of equilibration buffer (6 M urea, $30 \% \mathrm{w} / \mathrm{v}$ glycerin, $2 \% \mathrm{w} / \mathrm{v} \mathrm{SDS}, 50 \mathrm{mM}$ Tris- $\mathrm{HCl} \mathrm{pH} \mathrm{8.8)}$ with $2 \% \mathrm{w} / \mathrm{v}$ DTT and $0.5 \% \mathrm{v} / \mathrm{v}$ bromophenol blue solution $(0.25 \% \mathrm{w} / \mathrm{v}$ bromophenol blue, $1.5 \mathrm{M}$ Tris $-\mathrm{HCl}$ 
$\mathrm{pH} 8.8,0.4 \% \mathrm{w} / \mathrm{v}$ SDS) and incubated for $20 \mathrm{~min}$ at room temperature. Strips were removed and incubated in equilibration buffer with $4 \% \mathrm{w} / \mathrm{v}$ iodoacetamide and $0.5 \% \mathrm{v} / \mathrm{v}$ bromophenol blue solution for further $20 \mathrm{~min}$ at room temperature. Finally, the strips and $10 \mu \mathrm{L}$ SDS-PAGE molecular weight standard on filter paper were placed on top of the $20 \mathrm{~cm}$ x $20.5 \mathrm{~cm} 12 \%$ second-dimension gel (12\% v/ $\mathrm{v}$ acrylamide/bis solution, $375 \mathrm{mM}$ Tris, $\mathrm{pH} 8.8,0.1 \% \mathrm{v} / \mathrm{v}$ SDS, $1 / 2000$ TEMED, $0.05 \% \mathrm{v} / \mathrm{v}$ APS). Both were fixed in place with a $0.5 \% \mathrm{w} / \mathrm{v}$ agarose overlay. Gels were run in PROTEAN Plus Dodeca cell (Bio-Rad) at $70 \mathrm{~V}$ for approximately $14 \mathrm{~h}$, followed by $200 \mathrm{~V}$ until the bromophenol blue dye reached the bottom of the gel. The running buffer (25 mM Tris, $0.2 \mathrm{M}$ glycin, 0.1\% SDS) was cooled externally to $16^{\circ} \mathrm{C}$.

Gels/proteins were fixed overnight in 30\% ethanol, 2\% phosphoric acid, and washed $3 \times 20$ min with $2 \%$ phosphoric acid. The gels were equilibrated with $15 \%$ ammoniumsulfate, $18 \%$ ethanol, $2 \%$ phosphoric acid for $15 \mathrm{~min}$ and finally stained with colloidal Coomassie Blue for $48 \mathrm{~h}$.

\section{Gel scanning and image analysis}

After staining, gels were washed 10 min with pure water and scanned on a Molecular FX Scanner (Bio-Rad) at $100 \mu \mathrm{m}$ resolution. Protein spots were imaged first automatically and then manually and analysed using the PDQuest ${ }^{\mathrm{m}}$ soft- $^{-}$ ware (Bio-Rad). The normalization was carried out in total density in gel mode according to the manufacturer's recommendation.

\section{Matrix-assisted laser desorption ionization mass spectrometry (MALDI-MS)}

Gels were excised using the spot cutter of Bio-Rad and placed into 96-well microtiter plates. Excised gel spots were washed manually with $20 \mu \mathrm{L}$ of water for $10 \mathrm{~min}$ and destained twice, first with $15 \mu \mathrm{L}$ ammonium bicarbonate $50 \mathrm{mM}$ for $5 \mathrm{~min}$ and then with $15 \mu \mathrm{L} \mathrm{50 \%}$ ammonium bicarbonate $50 \mathrm{mM}-50 \%$ acetonitrile for $5 \mathrm{~min}$. Finally, the gel particles were covered by acetonitrile until gel pieces shrunk and left to dry for $10 \mathrm{~min}$. All gels/proteins were digested manually in situ with $4 \mu \mathrm{L}$ of ammonium bicarbonate $50 \mathrm{mM}$ containing $20 \mathrm{ng}$ trypsin (Sequencing Grade Modified Trypsin, Promega, Germany). After 15 min each gel piece was re-swelled with $10 \mu \mathrm{L}$ of ammonium bicarbonate $50 \mathrm{mM}$ and incubated for $4 \mathrm{~h}$ at $37^{\circ} \mathrm{C}$. After $4 \mathrm{~h}$ the reaction was stopped by adding $10 \mu \mathrm{L}$ of trifluoroacetic acid $1 \%$ containing $1.5 \%(\mathrm{w} / \mathrm{v})$ n-octyl-beta-D-glucopyranoside (OGP) (AppliChem). For the application of the samples, $4 \mu \mathrm{L}$ of peptide solution were loaded onto an MTP Anchor Chip Target 600/384 (Bruker Daltonics) previously prepared with a saturated solution of matrix, alpha-cyano-4-hydroxy-cinnamic acid (alpha-HCCA) (Bruker Daltonics, Bremen, Germany).
MALDI-MS was performed on an Ultraflex II MALDITOF/TOF (Bruker Daltonics) mass spectrometer equipped with a SmartBeam ${ }^{\text {tw }}$ laser and a LIFT-MS/MS facility. The instrument was operated in positive ion reflectron mode and an acceleration voltage of $25 \mathrm{keV}$ for the Peptide Mass Fingerprint (PMF) mode. Typically, 600 spectra, acquired at $100 \mathrm{~Hz}$, were summed and externally calibrated. In the case of MS/MS-CID the LIFT device was used for selection and fragmentation of the ions; the acceleration voltage in the ion source $8 \mathrm{kV}$, the Timed Ion Selector was set to $0.4 \%$ (relative to parent mass), and argon was used as collision gas ( 4-6 $\times 10-6$ mbar). Resulting fragments were further accelerated in a second source by $19 \mathrm{kV}$ and analysed by a two-stage gridless reflectron. Typically, 400 shots were accumulated for the parent ion signal and 1000 shots for the fragments. FlexControl ${ }^{\mathrm{Tm}}$ 3.0, and FlexAnalysis ${ }^{\mathrm{Tm}} 3.0$ were used as instrument control and processing software (Bruker Daltonics, Bremen, Germany).

A calibration standard was used for the external calibration of spectra (Peptide Calibration Standard for Mass Spectrometry, which covered the mass range $1000-4000 \mathrm{Da}$ (Bruker Daltonics). Typically, $1 \mu \mathrm{L}$ of the peptide calibration standard was spotted on 96 calibration positions of the Anchor Chip Target (Bruker Daltonics) containing the following peptides: angiotensin II (1046.5420 Da), angiotensin I (1296.6853 Da), substance P (1347.7361 Da), bombesin (1619.8230 Da), ACTH clip 1-17 (2093.0868 Da), ACTH clip 18-39 (2465.1990 Da), somatostatin 28 (3147.4714 Da) and OGP $1.5 \%(\mathrm{w} / \mathrm{v})$.

Internal calibration was achieved using trypsin autolysis products (m/z's 1045.564, 2211.108 and 2225.119) resulting in a mass accuracy of $\leq 50 \mathrm{ppm}$. Spectra were collected by the FlexControl software without smoothing or baseline subtraction and a peak resolution higher than 6000 or 7000 a.u. in case of DHB and CHCA matrixsample preparation, respectively. The spectra were sent to the FlexAnalysis software which labeled the peaks for protein identification by ProteinScape 1.3 or BioTools 3.1 (Bruker Daltonics).

Trypsin autolysis products, tryptic peptides of human keratin and matrix ions were automatically discarded by ProteinScape (mass control list). ProteinScape Score Booster feature was used to improve database search results by automatic iterative recalibrations and background eliminations. Protein scores greater than 53 were considered significant ( $\mathrm{p}<0.05$, Mascot) and an annotation as mouse protein as the top candidates was requested in the search when no restriction was applied to the species of origin. Identified proteins were checked individually for further considerations.

For PMF peak picking the snap peak detection algorithm, a signal to noise threshold of 6 , maximal number of peaks 100, a quality factor threshold 50 and baseline subtraction TopHat was applied. Peptide masses were searched against the Swiss-Prot database (download 2005-197 228 
sequences, 71501181 residues) employing the MASCOT server (in-house MASCOT-server, Matrix Sciences Ltd, http://www.matrixscience.com/, revision 2.0.0), taking into account carbamidomethyl of cysteines -Carbamidomethyl (C)- as fixed modification and possible oxidation of methionine -Oxidation (M)- as a variable modification but allowing one missed cleavage. Based on initial data, ion precursors were selected by ProteinScape for tandem MS data acquisition (by LIFT-TOF/TOF, Bruker Daltonics, Bremen, Germany). In the MASCOT MS/MS ions search, the restriction Mammalia was applied with peptide tolerance of (70 ppm and MS/MS tolerance of ( $0.9 \mathrm{Da}$ (fixed and variable modifications as PMF). The acceptance criteria for PMF-based identification were an individual ions score $>27$, at least five matching peptides and $10 \%$ peptide coverage of the theoretical sequences.

\section{Immunohistochemistry}

Livers, dissected from EGF-overexpressing mice aged between 7-9 months, were fixed in 4\% buffered paraformaldehyd and embedded in paraffin. $5 \mu \mathrm{m}$ thick sections were deparaffinized and rehydrated through a descending alcohol series followed by a 4 min washing step in destilled $\mathrm{H}_{2} \mathrm{O}$. Subsequently, antigen retrieval was performed in citrate buffer ( $\mathrm{pH}$ 6) by autoclaving the sections $15 \mathrm{~min}$ at $121^{\circ} \mathrm{C}$. The Envision kit (Dako, Hamburg, Germany) was used for immunohistochemistry.

The slides were rinsed with destilled $\mathrm{H}_{2} \mathrm{O}$ and after a 5 min incubation step in tris-buffered saline (washing buffer), endogenous peroxidase activity was blocked with DAKO Peroxidase blocking Reagent for 5 min followed by a second washing step. Thereafter, the sections were blocked for $10 \mathrm{~min}$ with protein-block serum free (Dako) and incubated with primary antibodies for $45 \mathrm{~min}$. Details of antibody dilutions with washing buffer are given in Additional file 1: Table S1. In the case of goat primary antibodies a rabbit-anti-goat bridging antibody (Dako) was employed. Specifically, the bound primary antibodies or bridging antibodies were detected by use of labelled polymer HRP Anti-Rabbit secondary antibody (Envision Kit; Dako) and the immunoreactivity was visualized by DAKO Liquid DAB Substrate Chromogen System in a $5 \mathrm{~min}$ incubation.

Finally, the sections were counterstained with Harris Haematoxylin for $2 \mathrm{~min}$, dehydrated in an ascending alcohol series, coverslipped and examined under a light microscope (Leica, Jülich, Germany).

\section{Bioinformatic analysis}

A total of $n=122$ disease regulated proteins were filtered for statistical significance at $\mathrm{p}<0.05$ (Table 1). This yielded $\mathrm{n}=96$ statistically significantly regulated proteins two of which had identical accession number, i.e. AAH81431 = ATP synthase $\mathrm{H}+$ transporting mitochondrial F0 complex, subunit $\mathrm{d}$ and BAC36241 = APOA1 but differed in their spot IDs as a result of posttranslational modifications. The statistically significantly regulated proteins were grouped into four different categories to yield 54 tumour specific (To), 9 up-regulated (UR), 19 down-regulated (DR) and 14 proteins only expressed in healthy non-transgenic control livers $(\mathrm{Co})$.

\section{Categorization of tumour regulated proteins based on ontology terms}

82 non-redundant tumour proteins covering To, UR and DR categories were considered and analysed for Ontologies using the GeneXplain software (v.2.4.1), the biological pathways tools Reactome (http://www.REACTOME.org) and KEGG (http://www.genome.jp/kegg) and WikiPathways (http://wikipathways.org). The tumour regulated proteins (To + UR + DR) were subjected to functional classification based on ontology terms and a p-value of $<0.01$ was considered to be significant. Moreover, disease regulated proteins were analysed with the Cytoscape software version 3.0.2 using the function GO-tree levels and number or \% of proteins for a given term (see Additional file 2: Table S2).

\section{Identification of master regulatory molecules and protein network construction for tumour proteins}

Master regulatory proteins were searched based on the designated workflow of the GeneXplain software. It is designed to find master regulatory molecules upstream of an input list of regulated tumour proteins. After annotation of the input datasets the tool for master regulator finding over GeneWays network (http://www.genexplain.com) was applied. Specifically, the GeneWays software is used to automatically extract, analyse, visualise and integrate molecular pathway data from the published peer reviewed literature. It is based on document sorting, term identification, term meaning disambiguation, information extraction, ontology, visualization and system integration [61]. The following filtering threshold was used, i.e. score cutoff (0.2), search collection (GeneWays hub), maximum radius $[4,10]$, FDR cutoff (0.05), Z-score cutoff (1.0), Penalty (0.1) and Decay factor (0.1) (Additional file 3: Table S3).

Protein network for disease regulated proteins were also constructed using the STRING software (http:// string-db.org/). The underlying database informs on known and predicted protein-protein interaction and the constructed networks are based on active prediction methods of Neighborhood, Gene Fusion, Co-occurrence, Co-expression, Databases and Textmining. Eventually, confidence scores were calculated for each interaction pair and only those above default cutoff scores (0.4) were selected.

Finally, mapping of pathways information from REACTOME, KEGG and WikiPathways have been implemented 
Table 1 Disease regulated proteins in HCC of EGF transgenic mice

\begin{tabular}{|c|c|c|c|c|c|c|c|c|c|c|c|c|c|c|c|c|}
\hline No. & Protein & $\begin{array}{l}\text { Gl number } \\
\text { (Protein) }\end{array}$ & $\begin{array}{l}\text { Accession } \\
\text { number } \\
\text { (Protein) }\end{array}$ & Gene Symbol & $\mathrm{Mr}$ & pl & Mascot score & Gels & $\mathrm{C}$ & $T$ & LB2 & LB3 & $\mathrm{p}$-value & Ratio T/C & $\begin{array}{l}\text { Cellular } \\
\text { location }\end{array}$ & References \\
\hline 1 & $\begin{array}{l}170 \mathrm{kDa} \text { glucose regulated protein } \\
\text { GRP170 precursor }\end{array}$ & 7643979 & AAF65544 & Hyou1 & 111 & 5 & 214 & 10 & 0 & 10 & 8 & 2 & & T & $E R, E S$ & {$[11,12]$} \\
\hline $2^{*}$ & 2-hydroxyphytanoyl-CoA lyase & 18204150 & AAH21360 & $\mathrm{HaCl} 1$ & 64 & 5.9 & 261 & 32 & 19 & 13 & 22 & 10 & 0.027 & 0.38 & $P$ & \\
\hline 3 & 3-phosphoglycerate dehydrogenase & 52353955 & NP_058662 & Phgdh & 57 & 6 & 204 & 14 & 0 & 14 & 11 & 3 & & T & & [13] \\
\hline $4^{*}$ & $\begin{array}{l}\text { 4931406C07Rik (Ester hydrolase C11orf54 } \\
\text { homolog) (spot 4342) }\end{array}$ & 71059921 & CAJ18504 & 4931406C07Rik & 35 & 5.8 & 184 & 35 & 17 & 18 & 24 & 11 & 0.033 & 1.5 & $\mathrm{~N}$ & \\
\hline $5^{*}$ & $\begin{array}{l}\text { 4931406C07Rik (Ester hydrolase C11orf54 } \\
\text { homolog) (spot 4349) }\end{array}$ & 71059921 & CAJ18504 & 4931406C07Rik & 35 & 5.8 & 195 & 33 & 15 & 18 & 22 & 11 & 0.244 & 1.9 & $\mathrm{~N}$ & \\
\hline 6 & $\begin{array}{l}\text { Acylpeptide hydrolase; N-acylaminoacyl } \\
\text { peptide hydrolase }\end{array}$ & 22122789 & NP_666338 & Apeh & 80 & 5.2 & 182 & 5 & 0 & 5 & 0 & 5 & & T & & [14] \\
\hline $7^{*}$ & Aldo-keto reductase family 1 , member $\mathrm{C} 12$ & 15215042 & AAH12643 & Akr1c12 & 37 & 6.1 & 135 & 24 & 14 & 10 & 15 & 9 & 0.301 & 1.9 & & \\
\hline 8 & $\begin{array}{l}\text { Akr1c18 protein (aldo-keto reductase } \\
\text { family } 1 \text {, member (18) }\end{array}$ & 19527284 & NP_598827 & Akr1c18 & 37 & 5.9 & 189 & 11 & 0 & 11 & 5 & 6 & & T & C & [15] \\
\hline $9^{*}$ & Alanyl-tRNA synthetase & 34610207 & NP_666329 & Aars & 107 & 5.4 & 178 & 4 & 0 & 4 & 0 & 4 & & T & C & \\
\hline 10 & Albumin 1 (spot 3707) & 33859506 & NP_033784 & Alb & 69 & 5.7 & 444 & 43 & 21 & 22 & 31 & 12 & 0.068 & 3.88 & C, ES & {$[15,16]$} \\
\hline 11 & Albumin 1 (spot 3712) & 33859506 & NP_033784 & Alb & 69 & 5.7 & 416 & 40 & 20 & 20 & 30 & 10 & 0.25 & 2.04 & C, ES & {$[15,16]$} \\
\hline 12 & Albumin 1 (spot 4506) & 33859506 & NP_033784 & Alb & 69 & 5.7 & 423 & 40 & 20 & 20 & 31 & 9 & & T & C, ES & {$[15,16]$} \\
\hline 13 & Albumin 1 (spot 4702) & 33859506 & NP_033784 & Alb & 69 & 5.7 & 355 & 42 & 20 & 22 & 31 & 11 & 0.069 & 1.85 & C, ES & {$[15,16]$} \\
\hline 14 & Albumin 1 (spot 5509) & 33859506 & NP_033784 & Alb & 69 & 5.7 & 473 & 38 & 18 & 20 & 30 & 8 & 0.392 & 3.59 & C, ES & {$[15,16]$} \\
\hline $15^{*}$ & Aldo-keto reductase family 1 , member $\mathrm{C} 14$ & 19527294 & NP_598833 & Akr1c14 & 37 & 5.9 & 189 & 11 & 0 & 11 & 5 & 6 & & T & & \\
\hline $16^{*}$ & Aldo-keto reductase family 1, member C6 & 13487925 & NP_085114 & Akr1c6 & 37 & 8.5 & 120 & 10 & 0 & 10 & 7 & 3 & & T & C & \\
\hline 17 & Aldolase 1, A isoform & 53733633 & AAH83932 & Aldoa & 39 & 9.2 & 213 & 12 & 1 & 11 & 11 & 1 & & T & & [17] \\
\hline $18^{*}$ & Aldolase 3 & 60687506 & NP_033787 & Aldoc & 39 & 6.5 & 153 & 5 & 0 & 5 & 4 & 1 & & T & M & \\
\hline 19 & Alpha enolase (spot 4501) & 58476212 & AAH89539 & $\begin{array}{l}\text { Gm5506 or } \\
\text { Enol1 }\end{array}$ & 47 & 6.4 & 341 & 45 & 22 & 23 & 33 & 12 & 0.24 & 0.22 & C & {$[3,13,18,19]$} \\
\hline 20 & Alpha enolase (spot 4516) & 58476212 & AAH89539 & $\begin{array}{l}\text { Gm5506 or } \\
\text { Enol1 }\end{array}$ & 47 & 6.4 & 338 & 40 & 21 & 19 & 30 & 10 & 0.161 & 0.47 & C & {$[3,13,18,19]$} \\
\hline 21 & Alpha enolase (spot 4524) & 58476212 & AAH89539 & $\begin{array}{l}\text { Gm5506 or } \\
\text { Enol1 }\end{array}$ & 47 & 6.4 & 338 & 42 & 22 & 20 & 31 & 11 & 0.021 & 0.53 & C & {$[3,13,18,19]$} \\
\hline 22 & Alpha enolase (spot 5510) & 58476212 & AAH89539 & $\begin{array}{l}\text { Gm5506 or } \\
\text { Enol1 }\end{array}$ & 47 & 6.4 & 330 & 45 & 22 & 23 & 34 & 11 & 0.234 & 0.76 & C & {$[3,13,18,19]$} \\
\hline $23^{*}$ & Alpha glucosidase 2 & 26326711 & BAC27099 & Ganab & 107 & 5.6 & 269 & 5 & 0 & 5 & 0 & 5 & & T & $E R, G$ & \\
\hline 24 & Annexin A6 & 31981302 & NP_038500 & Anxa6 & 76 & 5.3 & 267 & 5 & 0 & 5 & 0 & 5 & & T & C & {$[14,16]$} \\
\hline 25 & Apolipoprotein A-IV & 14789706 & AAH10769 & Apoa4 & 45 & 5.3 & 224 & 21 & 6 & 15 & 18 & 3 & 0.011 & 2.77 & ES & [20] \\
\hline 26 & Apolipoprotein E & 71060041 & CAJ18564 & Apoe & 36 & 5.5 & 220 & 31 & 14 & 17 & 21 & 10 & 0.01 & 3.97 & ES & {$[14,21]$} \\
\hline
\end{tabular}


Table 1 Disease regulated proteins in HCC of EGF transgenic mice (Continued)

\begin{tabular}{|c|c|c|c|c|c|c|c|c|c|c|c|c|c|c|c|c|}
\hline 27 & Apolipoprotein A-I (spot 2215) & 26345182 & BAC36241 & Apoa1 & 31 & 5.4 & 173 & 38 & 21 & 17 & 28 & 10 & 0.001 & 5.4 & S & {$[13,20,22]$} \\
\hline 28 & Apolipoprotein A-I (spot 3204) & 26345182 & BAC36241 & Apoa1 & 31 & 5.4 & 170 & 30 & 18 & 12 & & & & $\mathrm{~T}$ & S & {$[20,22]$} \\
\hline 29 & Arginase 1, liver & 7106255 & NP_031508 & Arg1 & 35 & 6.6 & 306 & 38 & 23 & 15 & 28 & 10 & 0.013 & 0.32 & C & {$[3,13,23,24]$} \\
\hline $30^{*}$ & Arginase type II & 6753110 & NP_033835 & Arg2 & 39 & 6.1 & 161 & 6 & 0 & 6 & 6 & 0 & & $\mathrm{~T}$ & M & \\
\hline 31 & Argininosuccinate synthetase 1 & 6996911 & NP_031520 & Ass1 & 47 & 8.5 & 175 & 15 & 15 & 0 & 10 & 5 & & C & M & {$[25-31]$} \\
\hline 32 & $\begin{array}{l}\text { ATP synthase, } \mathrm{H}+\text { transporting, } \\
\text { mitochondrial F0 complex, subunit d } \\
\text { (spot 2120) }\end{array}$ & 51980458 & AAH81431 & Atp5h & 19 & 5.3 & 148 & 37 & 20 & 17 & 25 & 12 & 0.002 & 0.33 & M & {$[32]$} \\
\hline 33 & $\begin{array}{l}\text { ATP synthase, } \mathrm{H}+\text { transporting, } \\
\text { mitochondrial F0 complex, subunit d } \\
\text { (spot 3203) }\end{array}$ & 51980458 & AAH81431 & Atp5h & 19 & 5.3 & 145 & 35 & 19 & 16 & 22 & 13 & & C & M & {$[32]$} \\
\hline $34^{*}$ & Beta 5-tubulin & 18088719 & AAH20946 & Tubb & 50 & 4.7 & 267 & 11 & 1 & 10 & 7 & 4 & & $\mathrm{~T}$ & Ck & \\
\hline $35^{*}$ & $\begin{array}{l}\text { Branched chain ketoacid dehydrogenase } \\
\text { E1, alpha polypeptide }\end{array}$ & 31982494 & NP_031559 & Bckdha & 50 & 8.4 & 237 & 26 & 18 & 8 & 20 & 6 & 0.018 & 0.5 & MM & \\
\hline $36^{*}$ & Butyryl Coenzyme A synthetase 1 & 16905127 & NP_473435 & Acsm1 & 65 & 6.6 & 119 & 4 & 4 & 0 & 0 & 4 & & C & MM & \\
\hline 37 & Cai protein (Pdia4) & 45219865 & AAH66857 & Pdia4 & 65 & 5.9 & 267 & 5 & 0 & 5 & 1 & 4 & & $\mathrm{~T}$ & ER & \\
\hline 38 & Capping protein alpha 1 subunit (Capza1) & 595917 & AAC00566 & Capza1 & 33 & 5.2 & 114 & 11 & 0 & 11 & 7 & 4 & & $\mathrm{~T}$ & Ck & [13] \\
\hline 39 & $\begin{array}{l}\text { Carbamoyl-phosphate synthetase } 1 \text {, } \\
\text { mitochondrial }\end{array}$ & 8393186 & NP_058768 & Cps1 & 165 & 6.3 & 350 & 31 & 22 & 9 & 22 & 9 & 0.023 & 0.2 & $M, C$ & {$[14,15,31,33,34]$} \\
\hline 40 & Carboxylesterase MH1 & 14331135 & BAB60698 & Ces1d & 62 & 6.2 & 168 & 4 & 0 & 4 & 0 & 4 & & $\mathrm{~T}$ & ER & {$[17,35]$} \\
\hline $41^{*}$ & $\begin{array}{l}\text { CDNA sequence BC021917 } \\
\text { (dihydroxyacetone kinase } 2 \text { homolog) }\end{array}$ & 21703976 & NP_663471 & Dak & 60 & 6.3 & 170 & 4 & 0 & 4 & 1 & 3 & & $\mathrm{~T}$ & & \\
\hline 42 & Creatine kinase & 10946574 & NP_067248 & $\mathrm{Ckb}$ & 43 & 5.3 & 181 & 4 & 0 & 4 & 0 & 4 & & $\mathrm{~T}$ & $M, C$ & [13] \\
\hline 43 & Cryz protein & 13277837 & AAH03800 & Cryz & 35 & 8.2 & 84 & 5 & 5 & 0 & 5 & 0 & & C & C & {$[36]$} \\
\hline 44 & Cu/Zn superoxide dismutase $1513495 \mathrm{~A}$ & 226471 & $1513495 \mathrm{~A}$ & Sod1 & 16 & 5.9 & 186 & 39 & 21 & 18 & 27 & 12 & 0.007 & 2.92 & & {$[13,22]$} \\
\hline 45 & $\begin{array}{l}\text { DEMSMC malate dehydrogenase, } \\
\text { cytosolic }\end{array}$ & 319837 & P14152 & Mdh1 & 37 & 5.9 & 138 & 31 & 17 & 14 & 19 & 12 & $4 \mathrm{E}-05$ & 0.27 & C & {$[37]$} \\
\hline $46^{*}$ & $\begin{array}{l}\text { Dhdh (dihydrodiol dehydrogenase } \\
\text { (dimeric)) protein }\end{array}$ & 21618806 & AAH31710 & Dhdh & 37 & 5.7 & 209 & 26 & 17 & 9 & 16 & 10 & $1 \mathrm{E}-04$ & 0.17 & & \\
\hline $47^{*}$ & Diacetyl/L-xylulose reductase & 50400594 & Q91X52 & Dcxr & 26 & 7.8 & 228 & 5 & 5 & 0 & 0 & 5 & & C & MEM & \\
\hline $48^{*}$ & $\begin{array}{l}\text { Dmgdh protein (Dimethylglycine } \\
\text { dehydrogenase, mitochondrial) }\end{array}$ & 12836171 & BAB23536 & Dmgdh & 97 & 7.6 & 184 & 8 & 8 & 0 & 5 & 3 & & C & M & \\
\hline $49^{*}$ & $\begin{array}{l}\text { Enoyl coenzyme A hydratase } 1 \text {, } \\
\text { peroxisomal }\end{array}$ & 7949037 & NP_058052 & Ech1 & 36 & 7.4 & 162 & 26 & 11 & 15 & 21 & 5 & 0.026 & 0.49 & $M, P$ & \\
\hline 50 & Eukaryotic translation elongation factor 2 & 33859482 & NP_031933 & Eef2 & 95 & 6.3 & 208 & 6 & 0 & 6 & 3 & 3 & & $\mathrm{~T}$ & C & [38] \\
\hline 51 & $\begin{array}{l}\text { Eukaryotic translation initiation factor } 5 \mathrm{~A} \\
\text { (elF-5A) }\end{array}$ & 124231 & NP_001160068 & Eif5a & 17 & 5.1 & 115 & 10 & 5 & 5 & 7 & 3 & 0.106 & 3.4 & $C, N$ & [14] \\
\hline $52^{*}$ & Farnesyl diphosphate synthetase & 19882207 & NP_608219 & Fdps & 41 & 5.4 & 158 & 5 & 0 & 5 & 0 & 5 & & $\mathrm{~T}$ & C & [39] \\
\hline
\end{tabular}


Table 1 Disease regulated proteins in HCC of EGF transgenic mice (Continued)

\begin{tabular}{|c|c|c|c|c|c|c|c|c|c|c|c|c|c|c|c|c|}
\hline $53^{*}$ & Fatty acid binding protein 5 , epidermal & 6754450 & NP_034764 & Fabp5 & 15 & 6.2 & 149 & 15 & 2 & 13 & 13 & 2 & 0.09 & 27.9 & C & \\
\hline 54 & Fibrinogen, alpha polypeptide & 33563252 & NP_034326 & Fga & 61 & 7 & 144 & 15 & 0 & 15 & 10 & 5 & & T & & {$[31,34]$} \\
\hline 55 & Fibrinogen, B beta polypeptide (spot 5602) & 33859809 & NP_862897 & $\mathrm{Fgb}$ & 55 & 6.5 & 238 & 35 & 15 & 20 & 23 & 12 & 0.001 & 2.41 & ES & [34] \\
\hline 56 & Fibrinogen, B beta polypeptide (spot 5612) & 33859809 & NP_862897 & Fgb & 55 & 6.5 & 244 & 33 & 15 & 18 & 22 & 11 & 0.187 & 3.54 & ES & [34] \\
\hline 57 & Fibrinogen, gamma polypeptide & 18044708 & AAH19828 & Fgg & 49 & 5.5 & 196 & 12 & 1 & 11 & 5 & 7 & & T & ES & {$[31,40]$} \\
\hline 58 & FK506 binding protein 4 & 6753882 & NP_034349 & Fkbp4 & 52 & 5.5 & 154 & 4 & 0 & 4 & 1 & 3 & & T & $C, N$ & {$[13,14]$} \\
\hline 59 & GDP dissociation inhibitor 2 (GDI 2) & 38197560 & AAH61767 & Gdi2 & 51 & 5.8 & 220 & 5 & 0 & 5 & 0 & 5 & & T & $\begin{array}{l}\text { G, } C \\
\text { MEM }\end{array}$ & [14] \\
\hline 60 & Glutathione peroxidase 1 & 6680075 & NP_032186 & Gpx1 & 22 & 6.2 & 215 & 25 & 18 & 7 & 18 & 7 & $2 \mathrm{E}-05$ & 0.28 & $C, M$ & {$[41-43]$} \\
\hline 61 & Glutathione S-transferase, mu 2 & 6680121 & NP_032209 & Gstm2 & 26 & 7.6 & 222 & 11 & 1 & 10 & 7 & 4 & & T & C & {$[14,15]$} \\
\hline 62 & Glycine N-methyltransferase (spot 4256) & 34013296 & AAL06142 & Gnmt & 33 & 6.9 & 214 & 23 & 23 & 0 & 17 & 6 & & C & C & {$[15,40,44,45]$} \\
\hline 63 & Glycine N-methyltransferase (spot 5269) & 34013296 & AAL06142 & Gnmt & 33 & 6.9 & 226 & 22 & 22 & 0 & 15 & 7 & & C & C & {$[15,40,44,45]$} \\
\hline 64 & Glycine N-methyltransferase (spot 9105) & 34013296 & AAL06142 & Gnmt & 33 & 6.9 & 218 & 20 & 20 & 0 & 15 & 5 & & C & C & {$[15,40,44,45]$} \\
\hline 65 & Glycyl-tRNA synthetase & 21264024 & Q9CZD3 & Gars & 82 & 6.2 & 180 & 5 & 0 & 5 & 0 & 5 & & T & C & [46] \\
\hline 66 & $\begin{array}{l}\text { Haao protein (3-hydroxyanthranilate } \\
\text { 3,4-dioxygenase) }\end{array}$ & 15277547 & AAH12872 & Haao & 33 & 6 & 420 & 35 & 22 & 13 & 27 & 8 & 0.006 & 0.24 & C & [14] \\
\hline 67 & Hal (histidine ammonia lyase) protein & 35505393 & AAH57637 & $\mathrm{Hal}$ & 72 & 5.9 & 301 & 6 & 6 & 0 & 0 & 6 & & C & $C$ & [47] \\
\hline 68 & Hemopexin & 23956086 & NP_059067 & Hpx & 51 & 9 & 231 & 16 & 2 & 14 & 11 & 5 & 0.323 & 7.27 & ES & [48] \\
\hline 69 & $\begin{array}{l}\text { Heterogeneous nuclear } \\
\text { ribonucleoprotein L (hnRNPL) }\end{array}$ & 33667042 & NP_796275 & Hnrnpl & 60 & 6.6 & 156 & 8 & 0 & 8 & 8 & 0 & & T & N & [13] \\
\hline 70 & HSP60 (spot 2604) & 1334284 & CAA37654 & Hspd1 & 58 & 5.3 & 298 & 15 & 7 & 8 & 6 & 9 & 0.008 & 0.4 & MM & {$[13,14,35]$} \\
\hline 71 & HSP60 (spot 2610) & 1334284 & CAA37654 & Hspd1 & 58 & 5.3 & 298 & 14 & 7 & 7 & 6 & 8 & 0.012 & 0.5 & MM & {$[13,14,35]$} \\
\hline $72^{*}$ & Hypothetical protein LOC68347 & 58037115 & NP_080962 & 0610011F06Rik & 23 & 5.8 & 125 & 29 & 15 & 14 & 21 & 8 & 0.014 & 0.39 & & \\
\hline $73^{*}$ & Inosine triphosphatase & 31982664 & NP_080198 & Itpa & 22 & 5.4 & 139 & 5 & 0 & 5 & 5 & 0 & & T & C & \\
\hline 74 & Interleukin 1 receptor antagonist protein & 238585 & AAB20265 & $\| 1 \mathrm{rn}$ & 18 & 5.5 & 121 & 7 & 0 & 7 & 6 & 1 & & T & $S, C$ & {$[35-37,41-43,45-50]$} \\
\hline $75^{*}$ & $\begin{array}{l}\text { Interleukin } 25 \text { or UPF0556 protein } \\
\text { C19orf10 homolog precursor }\end{array}$ & 18250288 & NP_543027 & D17Wsu104e & 18 & 5.9 & 89 & 13 & 6 & 7 & 9 & 4 & 0.23 & 2.1 & ES & \\
\hline $76^{*}$ & Kininogen 1 & 12963497 & NP_075614 & Kng1 & 48 & 5.7 & 217 & 21 & 8 & 13 & 19 & 2 & 0.091 & 2.8 & ES & \\
\hline 77 & Lamin-A/C & 15929761 & AAH15302 & Lmna & 74 & 6.6 & 199 & 12 & 0 & 12 & 10 & 2 & & T & N & {$[13,15]$} \\
\hline $78^{*}$ & LIM and SH3 protein 1 & 6754508 & NP_034818 & Lasp1 & 30 & 6.7 & 156 & 7 & 0 & 7 & 6 & 1 & & T & Ck & \\
\hline 79 & Liver fructose-1,6-bisphosphatase & 6688689 & CAB65244 & Fbp1 & 37 & 6.2 & 281 & 29 & 18 & 11 & 17 & 12 & 0.013 & 0.35 & & {$[14,34,40]$} \\
\hline $80^{*}$ & Lysophospholipase 1 & 6678760 & NP_032892 & Lypla1 & 25 & 5.9 & 134 & 25 & 13 & 12 & 20 & 5 & 0.25 & 0.25 & M & \\
\hline 81 & Major urinary protein & 1839508 & AAB47130 & Mup14 & 19 & 4.7 & 138 & 6 & 6 & 0 & 6 & 0 & & C & S & {$[51,52]$} \\
\hline $82^{*}$ & Major vault protein & 12003287 & AAG43520 & Mvp & 96 & 5.4 & 238 & 4 & 0 & 4 & 0 & 4 & & T & C & \\
\hline 83 & & 31560132 & NP_080977 & Pbld1 & 32 & 5.1 & 318 & 25 & 19 & 6 & 19 & 6 & 0.065 & 0.38 & & {$[3,14,40]$} \\
\hline
\end{tabular}


Table 1 Disease regulated proteins in HCC of EGF transgenic mice (Continued)

\begin{tabular}{|c|c|c|c|c|c|c|c|c|c|c|c|c|c|c|c|c|}
\hline & $\begin{array}{l}\text { MAWD binding protein homolog } 1 \text { or } \\
\text { Phenazine biosynthesis-like domain- } \\
\text { containing protein } 1\end{array}$ & & & & & & & & & & & & & & & \\
\hline $84^{*}$ & $\begin{array}{l}\text { Mitochondrial acyl-CoA thioesterase } 1 \text { OR } \\
\text { Acyl-CoA thioesterase } 2\end{array}$ & 40538846 & NP_598949 & Acot2 & 50 & 7 & 123 & 6 & 6 & 0 & 1 & 5 & & C & M & \\
\hline 85 & $\begin{array}{l}\text { NADH dehydrogenase (ubiquinone) } 1 \\
\text { alpha subcomplex, } 8\end{array}$ & 21312012 & NP_080979 & Ndufa8 & 20 & 8.8 & 145 & 4 & 4 & 0 & 4 & 0 & & C & M & {$[34,53]$} \\
\hline 86 & $\begin{array}{l}\text { NADH dehydrogenase (ubiquinone) } \\
\text { Fe-S protein } 1 \text { (Ndufs } 1 \text { ) }\end{array}$ & 26331822 & BAC29641 & Ndufs1 & 80 & 5.5 & 240 & 5 & 5 & 0 & 0 & 5 & & C & M & [14] \\
\hline 87 & $\begin{array}{l}\text { NADH dehydrogenase (ubiquinone) } \\
\text { flavoprotein } 1\end{array}$ & 19526814 & NP_598427 & Ndufv1 & 51 & 8.5 & 151 & 4 & 0 & 4 & 3 & 1 & & T & M, ES & [53] \\
\hline 88 & Nit protein 2 (spot 5315) & 12963555 & NP_075664 & Nit2 & 31 & 6.2 & 347 & 34 & 18 & 16 & 24 & 10 & & $C$ & & {$[3,13]$} \\
\hline 89 & Nit protein 2 (spot 6201) & 12963555 & NP_075664 & Nit2 & 31 & 6.2 & 345 & 30 & 16 & 14 & 22 & 8 & 0.295 & 0.8 & & {$[3,13]$} \\
\hline $90^{*}$ & Nucb1 (nucleobindin 1) protein & 49117484 & AAH72554 & Nucb1 & 53 & 5 & 184 & 8 & 0 & 8 & 8 & 0 & & T & $\begin{array}{l}\text { G, C, } \\
\text { MEM }\end{array}$ & \\
\hline 91 & Peroxiredoxin 6 (spot 4207) & 6671549 & NP_031479 & Prdx6 & 25 & 5.7 & 282 & 40 & 21 & 19 & 30 & 10 & 0.132 & 2.3 & $C, L$ & [3] \\
\hline 92 & Peroxiredoxin 6 (spot 5216) & 6671549 & NP_031479 & Prdx6 & 25 & 5.7 & 280 & 38 & 20 & 18 & 28 & 10 & 0.018 & 0.3 & $C, L$ & [3] \\
\hline 94 & Plasminogen & 200403 & AAA50168 & Plg & 91 & 6 & 243 & 9 & 0 & 9 & 6 & 3 & & T & S & {$[33,54-56]$} \\
\hline $95^{*}$ & $\begin{array}{l}\text { Poly }(\mathrm{rC}) \text { binding protein } 2 \text {; } \\
\text { heterogeneous nuclear ribonucleoprotein } \\
\mathrm{X} \text { or Poly }(\mathrm{r} C) \text { binding protein } 1\end{array}$ & 6754994 & NP_035995 & Pcbp1 & 38 & 6.4 & 189 & 8 & 0 & 8 & 8 & 0 & & T & $\mathrm{N}$ & \\
\hline 96 & Agmatine ureohydrolase (agmatinase) & 20848362 & XP_131722 & Agmat & 38 & 8 & 108 & 24 & 16 & 8 & 19 & 5 & 0.003 & 0.1 & ES & \\
\hline 97 & Prohibitin & 54035592 & AAH83354 & $\mathrm{Phb}$ & 30 & 5.4 & 335 & 39 & 21 & 18 & 28 & 11 & 0.018 & 0.6 & M & [13] \\
\hline $98^{*}$ & $\begin{array}{l}\text { Psmd11 (proteasome (prosome, } \\
\text { macropain) } 26 \mathrm{~S} \text { subunit, non-ATPase, 11) } \\
\text { protein }\end{array}$ & 33585718 & AAH55457 & Psmd11 & 47 & 6.1 & 258 & 4 & 0 & 4 & 0 & 4 & & T & C & \\
\hline 99 & Pyridoxine 5'-phosphate oxidase & 19527238 & NP_598782 & Pnpo & 30 & 8.4 & 120 & 24 & 14 & 10 & 16 & 8 & 0.026 & 0.3 & & {$[15,40]$} \\
\hline 100 & $\begin{array}{l}\text { Pyruvate kinase } 3 \text { or pyruvate kinase, } \\
\text { muscle isoform M2 }\end{array}$ & 31981562 & NP_035229 & Pkm & 58 & 7.9 & 274 & 7 & 0 & 7 & 4 & 3 & & T & M & [57] \\
\hline 101 & $\begin{array}{l}\text { Pzp protein (a2-macroglobulin) or } \\
\text { Pregnancy zone protein }\end{array}$ & 34785996 & AAH57983 & Pzp & 166 & 6.2 & 151 & 14 & 2 & 12 & 9 & 5 & & T & ES & [58] \\
\hline 102 & Retinol binding protein 4, plasma & 33859612 & NP_035385 & Rbp4 & 23 & 5.6 & 144 & 19 & 2 & 17 & 14 & 5 & 0.129 & 12.7 & ES & [3] \\
\hline $104^{*}$ & $\begin{array}{l}\text { RIKEN cDNA } 2410004 \mathrm{H} 02 \text { or Aldehyde } \\
\text { dehydrogenase family } 16 \text { member A1 }\end{array}$ & 26080429 & NP_666066 & Aldh16a1 & 85 & 5.8 & 114 & 4 & 0 & 4 & 0 & 4 & & T & & \\
\hline $105^{*}$ & Ribosomal protein S12 & 34849622 & AAH58460 & Rps12 & 15 & 7.3 & 90 & 8 & 1 & 7 & 6 & 2 & 0.008 & 2 & C & \\
\hline
\end{tabular}


Table 1 Disease regulated proteins in HCC of EGF transgenic mice (Continued)

\begin{tabular}{|c|c|c|c|c|c|c|c|c|c|c|c|c|c|c|c|c|}
\hline $106^{*}$ & $\begin{array}{l}\text { Sars1 protein or Seryl-aminoacyl-tRNA } \\
\text { synthetase }\end{array}$ & 14250361 & AAH08612 & Sars & 58 & 5.9 & 199 & 4 & 0 & 4 & 0 & 4 & & $\mathrm{~T}$ & C & \\
\hline 107 & Selenium binding protein 1 & 22164798 & NP_033176 & Selenbp1 & 53 & 5.9 & 336 & 31 & 19 & 12 & 21 & 10 & 0.061 & 0.5 & $\begin{array}{l}\text { C, MEM, } \\
\text { N }\end{array}$ & [14] \\
\hline 108 & $\begin{array}{l}\text { Serine (or cysteine) proteinase inhibitor, } \\
\text { clade } B \text {, member } 6 a\end{array}$ & 6678097 & NP_033280 & Serpinb6a & 43 & 5.4 & 137 & 5 & 0 & 5 & 0 & 5 & & T & C & [13] \\
\hline $109^{*}$ & Serpinb1a protein & 12834891 & BAB23079 & Serpinb1a & 43 & 5.7 & 255 & 8 & 8 & 0 & 4 & 4 & & C & $C$ & \\
\hline 110 & Serum amyloid P-component & 38174334 & AAH61125 & Apcs & 26 & 6 & 141 & 4 & 0 & 4 & 0 & 4 & & T & ES & [14-16] \\
\hline $111^{*}$ & Sorcin & 13385076 & NP_079894 & Sri & 20 & 4.9 & 129 & 7 & 0 & 7 & 6 & 1 & & $\mathrm{~T}$ & C, MEM & \\
\hline $112^{*}$ & $\begin{array}{l}\text { T43799 proteasome protein p45/SUG } \\
\text { [imported] }\end{array}$ & 11265288 & P62198 & Psmc5 & 46 & 7.6 & 222 & 6 & 0 & 6 & 6 & 0 & & $\mathrm{~T}$ & $C, N$ & \\
\hline 113 & $\begin{array}{l}\text { T-complex protein 1, theta subunit } \\
\text { (TCP-1-theta) (CCT-theta) }\end{array}$ & 12846632 & BAB27244 & Cct8 & 50 & 5.5 & 189 & 5 & 0 & 5 & 0 & 5 & & $\mathrm{~T}$ & C & [15] \\
\hline 114 & Transglutaminase 2, C polypeptide & 6678329 & NP_033399 & $\operatorname{Tgm} 2$ & 77 & 5 & 240 & 6 & 0 & 6 & 3 & 3 & & $\mathrm{~T}$ & C, MEM & [14] \\
\hline 115 & Transthyretin & 7305599 & NP_038725 & Ttr & 16 & 5.5 & 127 & 18 & 6 & 12 & 12 & 6 & 0.169 & 3 & ES & {$[16,20]$} \\
\hline 116 & $\begin{array}{l}\text { Tumor metastatic process-associated pro- } \\
\text { tein NM23 }\end{array}$ & 51980604 & AAH82178 & Nme1 & 17 & 6.4 & 134 & 9 & 0 & 9 & 7 & 2 & & $\mathrm{~T}$ & & {$[13,14]$} \\
\hline $117^{*}$ & $\begin{array}{l}\text { Uap1l1 (UDP-N-acteylglucosamine } \\
\text { pyrophosphorylase 1-like 1) protein }\end{array}$ & 28175154 & AAH43307 & Uap1l1 & 57 & 5.2 & 168 & 4 & 0 & 4 & 0 & 4 & & $\mathrm{~T}$ & & \\
\hline 118 & UDP-glucose dehydrogenase & 6678499 & NP_033492 & Ugdh & 55 & 7.4 & 307 & 14 & 0 & 14 & 13 & 1 & & $\mathrm{~T}$ & & {$[46]$} \\
\hline 119 & $\begin{array}{l}\text { Galectin-3 or Lectin, galactose binding, } \\
\text { soluble } 3\end{array}$ & 52987 & CAA34736 & Lgals3 & 28 & 8.8 & 136 & 6 & 0 & 6 & 5 & 1 & & T & $\mathrm{N}, \mathrm{C}$ & [13] \\
\hline $120^{*}$ & $\begin{array}{l}\text { V-crk sarcoma virus CT10 oncogene } \\
\text { homolog }\end{array}$ & 56205173 & CAI24083 & Crk & 34 & 5.3 & 187 & 8 & 0 & 8 & 8 & 0 & & $\mathrm{~T}$ & C, MEM & \\
\hline 121 & Vimentin & 31982755 & NP_035831 & Vim & 54 & 5 & 260 & 26 & 11 & 15 & 21 & 5 & 0.022 & 4 & Ck & {$[13,35]$} \\
\hline 122 & Vitamin D-binding protein & 193446 & AAA37669 & Gc & 53 & 5.2 & 229 & 32 & 15 & 17 & 22 & 10 & 0.175 & 1.6 & ES & {$[59,60]$} \\
\hline
\end{tabular}

Abbreviations: $C$, cytosol: $C k$, cytoskeleton: $M$, mitochondria; $N$ nucleus: $P$, peroxisome; $E S$, extracellular space; $E R$, endoplasmic reticulum; $G$, golgi: $L$, lysosome: MEM membrane: MM, mitochondrial matrix: $S$, secreted.

The proteins are sorted in alphabetical order, and the NCBI annotation is given in the accession number column. Molecular weight, pl, and MASCOT scores are also given. The column "Gels", " $\mathrm{C}$ " (C $=$ control) and " $T$ " $(\mathrm{T}=$ tumour) indicate the frequency of positive identification of proteins in a total of 48 independent gels, whereas "LB2" and "LB3" (LB=lysis buffer) refers to the different lysis buffers employed. Furthermore, references are given for those proteins which have already been described as HCC-associated whereas those marked with a star (*) are so far unknown as EGFR disease regulated in hepatocellular carcinoma. 
over protein networks using information of known pathways and sustained proteins connecting these pathways in a given network.

\section{Results}

The histopathology and oncogenomics of EGF induced liver cancers was previously reported [6] and an important finding of the study was the $100 \%$ incidence of malignant tumour formation in less than one year after birth. Notably, a sequence of events was observed that initially consisted of diffuse large cell dysplasia followed by multiple dysplastic foci and nodules and growth of HCC. Figure $1 \mathrm{~A}$ and B depict the histopathology of healthy non-transgenic control liver and EGF induced tumours, respectively.

\section{Image analysis of differentially expressed proteins}

After protein extraction 2DE was performed. Subsequently, the gels were scanned on a Bio-Rad Molecular FX Scanner at a $100 \mu \mathrm{m}$ resolution. Image analysis was done with the PDQuestTM software and spots were detected automatically. A total of 122 proteins differed in expression or were de novo expressed when 2DE gels of non-transgenic controls and HCC mice were compared (see Table 1 for detailed information on the proteins identified and Figure 1E-G depicting examples of zoomin-gels of some regulated proteins). Among them are 96 statistically significantly regulated proteins $(p \leq 0.05)$ of which 63 were significantly up-regulated $\left(\mathrm{ratio}_{\mathrm{HCC} / \mathrm{con}-}\right.$ trol $\geq 2$ ) and included fibrinogen and subunits of it, vimentin, $\mathrm{Cu} / \mathrm{Zn}$ superoxide dismutase, and apolipoprotein E (Figure 1F (I-IV), while 33 proteins were repressed in expression $\left(\mathrm{ratio}_{\mathrm{HCC} / \mathrm{control}} \leq 0.6\right)$ and included arginase 1, Dhdh protein, glutathione peroxidase 1 and agmatine ureohydrolase (Figure 1G (I-IV) and Table 1).

\section{Identification of proteins by MS analysis}

A reference 2-DE map of mouse liver and serum proteins was constructed that consists of more than $n=500$ proteins [2,7]. Note, in our previous efforts we identified $\mathrm{n}=25$ serum proteins as regulated in the EGF transgenic disease model. Among them were alpha-fetoprotein, clusterin, fibrinogen- $\alpha$ and $-\gamma$, serum amyloid component $\mathrm{P}$ and several apolipoproteins all of which were significantly up-regulated. Based on the combined use of 2DE and MALDI-MS a total of $\mathrm{n}=122$ differentially expressed proteins were identified (Table 1) and included isoforms as well as post translational modifications of albumin (5 up-regulated spots), alpha enolase (4 down-regulated spots), apoliproptein A-I (2 up-regulated spots), ATP synthase $\mathrm{H}+$ transporting mitochondrial (2 down-regulated spots), fibrinogen beta (2 up-regulated spots), glycine $\mathrm{N}$-methyltransferase (3 spots, in controls only), hsp60 (2 down-regulated spots), nit protein 2 (2 down-regulated spots), peroxiredoxin 6 (1 up-regulated spot and 1 down-regulated spot), and 4931406C07Rik (2 up-regulated spots) (see Table 1). Importantly, a total of $\mathrm{n}=37$ so far unknown disease regulated proteins were identified that can now be related to EGF induced liver cancer. These are marked with an asterisk in Table 1.

Furthermore, a comparison of serum and liver proteoms revealed $\mathrm{n}=10$ proteins to be regulated in common, thus evidencing leakage of tumour proteins into systemic circulation (Table 2). Among them was serum AFP; it's up-regulation and that of others was confirmed by Western blot analysis (Figure 2A-E). Likewise, apolipoprotein $\mathrm{E}$ was up-regulated both in serum and tumour samples, the ratio $\mathrm{HCC} /$ control being 2.2 and 3.9, respectively. In a previous study on human HCC increased expression of ApoE was observed in $88 \%$ of study cases; however, gene ApoE expression and serum levels were unchanged to suggest its accumulation and impaired secretion [21]. Two isoforms of alpha-2-macroglobulin were up-regulated in serum of HCC-bearing mice (spot 1: ratio $_{\mathrm{HCC} / \text { control }}=1.8$; spot 2: $\mathrm{ratio}_{\mathrm{HCC} / \text { control }}=3.2$ ). Its expression was exclusively associated with tumours. Finally, serum amyloid component $\mathrm{P}$ was up to 10-fold up-regulated in serum and its tissue expression was tumour specific (Table 2).

\section{Immunohistochemistry of disease-regulated proteins}

To further evidence disease regulated proteins and to provide information on their subcellular localization a total of $n=8$ proteins were studied by immunohistochemistry. Five of them were selected for their novelty (see Table 1) while amphiregulin and epiregulin were chosen for their importance in the EGF-signalling pathway. Furthermore, HNF4 $\alpha$ was studied for its pivotal role in liver cancer [62]. Depicted in Figure 3 are immunohistochemistry stainings performed with EGF transgenic livers to confirm regulation and predominant cytoplasmic expression of arginase II. Note, ARG2 is only expressed in $\mathrm{HCC}$ and recent evidence suggest modulation of arginine levels in the extracellular milieu to be part of an immune escape mechanism whereby lack of local arginine weakens tumour-infiltrating lymphocytes as $\mathrm{T}$ cells require adequate argine levels [63]. Likewise, the tumour specific and cytoplasmic expression of the F-actin capping protein $\alpha 1$ subunit (CAPZA1) and the predominant nuclear expression of tubulin $\beta$ that was particularly visible beneath the liver capsule may possible promote microtubule stability and interactions of microtubules with endogenous proteins. Furthermore, the induced and predominat cytoplasmic expression of the GDP dissociation inhibitor 2 (GDI2) protein is part of the control of vesicular trafficking. This protein is known to regulate GDP-GTP exchange amongst members of the Rab family of proteins. The 


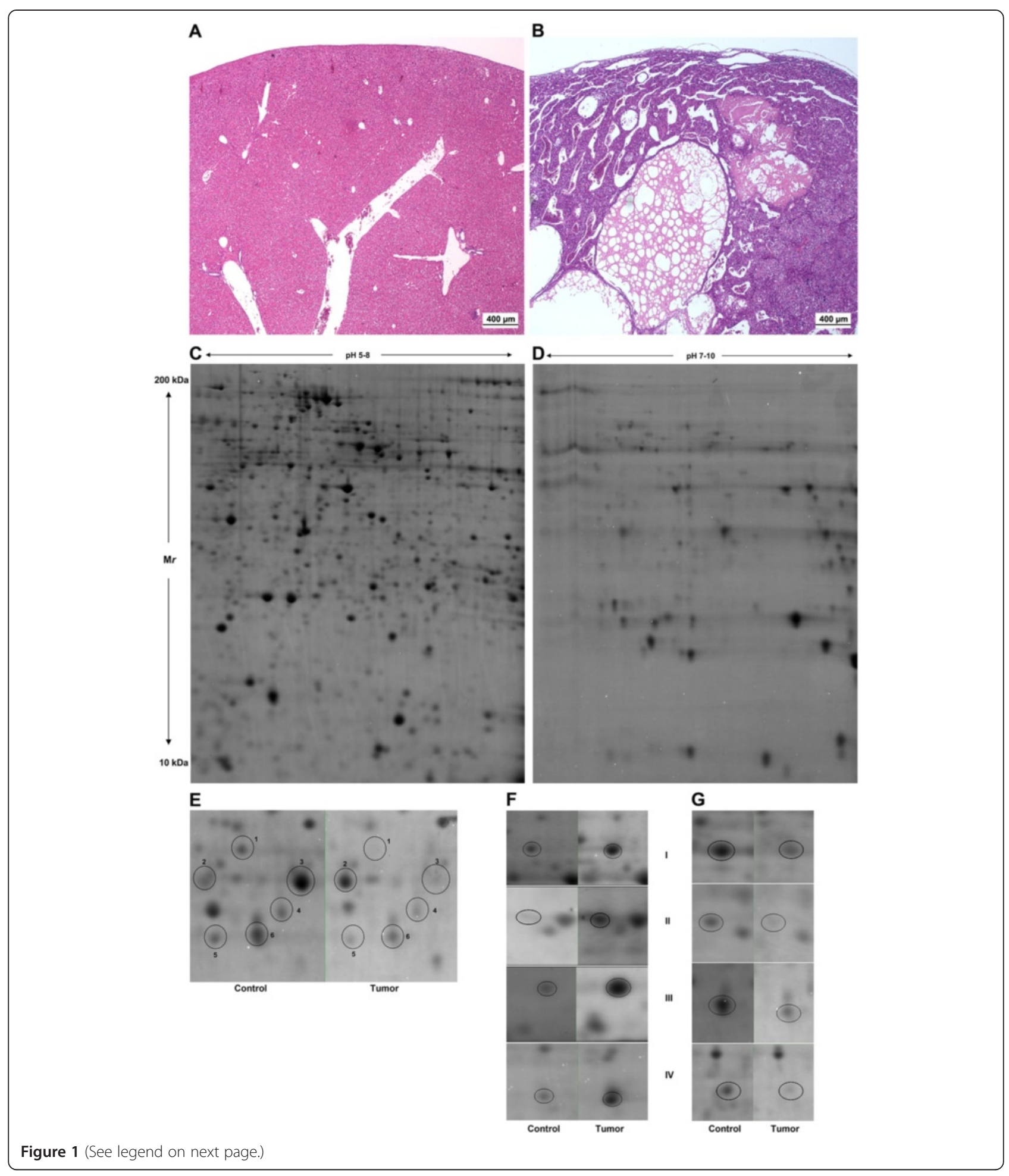


(See figure on previous page.)

Figure 1 Liver proteome mapping of healthy non-transgenic control and EGF transgenic mice. (A) Histopathology of a well-organized normal liver tissue of a non-transgenic control (image magnification 25-fold). (B) Histopathology of completely disorganized tissue of advanced HCC showing multilayered hepatocytic trabeculae besides solid areas, peliosis-like intratumourous vasectasias and focal necroses (light red) (image magnification 25-fold). (C) Zoom-in 2D gel image of healthy non-transgenic control liver extracts in the pH range of 5-8. (D) Zoom-in 2D gel image of healthy non-transgenic control liver extracts in the $\mathrm{pH}$ range of 7-10.Panel $\mathrm{E}$ to $\mathrm{G}$ depict examples of zoom-in 2D gels of regulated proteins. (E) Spot 1: glycine N-methyltransferase, identified in control samples only; Spot 2: peroxiredoxin 6, up-regulated in tumour samples; Spot 3: peroxiredoxin 6, down-regulated in tumour samples; Spot 4: lysophospholipase 1, down-regulated in tumour samples; Spot 5: hypothetical protein LOC68347, down-regulated in tumour samples; Spot 6: glutathione peroxidase 1, down-regulated in tumour samples. (F) Examples of up-regulated mouse liver proteins: fibrinogen $\beta$ (I), vimentin (II), Cu/Zn superoxide dismutase (III), and apolipoprotein E (IV). (G) Examples of down-regulated mouse liver proteins: arginase 1 (I), Dhdh protein (II), glutathione peroxidase 1 (III) and predicted: agmatine ureohydrolase (IV).

tumour specific and cytoplasmic expression of amphiregulin supports the notion of a switch in autocrine signalling and it has been reported that amphiregulin is a prognostic marker for poor outcome of a variety of malignancies including colorectal liver metastasis [64]. Finally, the repressed nuclear expression of HNF4A was not unexpected and confirms earlier findings [62].

\section{Comparison of disease regulated proteins in mouse and human HCC}

Based on the information given in Table 1 the Human Protein Atlas depository (www.proteinatlas.org, version 12) was interrogated. As shown in Additional file 4: Table S4 48 out of 96 mouse liver cancer regulated proteins were likewise regulated in human HCC. It should be noted that for some proteins several antibodies were used to study their expression; only representative data were considered. Importantly, out of the 54 proteins uniquely expressed in mouse liver tumours $n=11$ were likewise uniquely expressed in human HCC thus evidencing clinical significance of our findings.

\section{Comparison of gene and protein expression in EGF induced liver cancer}

We compared our previously published transcriptomic data of EGF induced liver cancers with the proteomic data obtained in the present study. Such comparisons revealed $n=22$ genes to be significantly regulated of which $\mathrm{n}=17$ are in common regulated whereas for $\mathrm{n}=5$ genes transcript expression was opposite to that of the coded proteins (see Additional file 5: Table S5).

\section{Classifications of disease regulated protein by Gene Ontology (GO)}

82 of the 96 significantly regulated proteins were mapped to 40 different biological processes (see Figure 4A) of which prominent examples are regulation of arginine metabolism and amino acid import, regulation of CDC42 protein signal transduction', cellular response to oxidative stress, hydrogen peroxide and superoxide, glycolysis and gluconeogenesis, regulation of cholesterol transport, protein-lipid complex and plasma lipoprotein particle remodeling, positive regulation of steroid metabolic process, negative regulation of calcium ion transmembrane transporter activity and release of sequestered calcium ion into cytosol by sarcoplasmic reticulum, (see Additional file 6: Table S6).

In Figure 4A-C the $\mathrm{GO}$ biological process, cellular components and molecular functions are depicted.

Note, some of the ontology terms could be grouped, i.e. chaperone-mediated protein complex assembly and folding, endoplasmic reticulum unfolded protein response,

Table 2 Proteins regulated in common in tumour tissue and serum of EGF transgenic mice

\begin{tabular}{|c|c|c|c|c|}
\hline No. & Protein & Accession number & Ratio $_{\mathrm{HCC} / \text { control (serum) }}$ & Ratio $_{\mathrm{HCC} / \text { control }}$ (liver) \\
\hline 1 & Alpha-fetoprotein & gi|42542817 & 2 & up (by Western blot) \\
\hline 2 & Apolipoprotein A1 & gi|26345182 & tumour & Spot 1: 5.4 Spot 2: tumour \\
\hline 3 & Apolipoprotein E & gi|6753102 & 2.2 & 3.9 \\
\hline 4 & Carboxylesterase precursor & gi|2921308 & tumour & tumour \\
\hline 5 & Fibrinogen, alpha polypeptide & gi|33563252 & tumour & tumour \\
\hline \multirow[t]{2}{*}{6} & Fibrinogen, beta polypeptide & gi|33859809 & tumour & Spot 1: 2.4 \\
\hline & & & & Spot 2: 3.5 \\
\hline 7 & Fibrinogen, gamma polypeptide & gi|19527078 & tumour & tumour \\
\hline 8 & Major urinary protein 1 & gi|8569601 & 0,1 & control \\
\hline \multirow[t]{2}{*}{9} & Pzp (A2mg protein) & gi|34785996 & Spot 1: 1.8 & tumour \\
\hline & & & Spot 2: 3.2 & \\
\hline 10 & Serum amyloid P-component & gi|38174334 & 10 & tumour \\
\hline
\end{tabular}



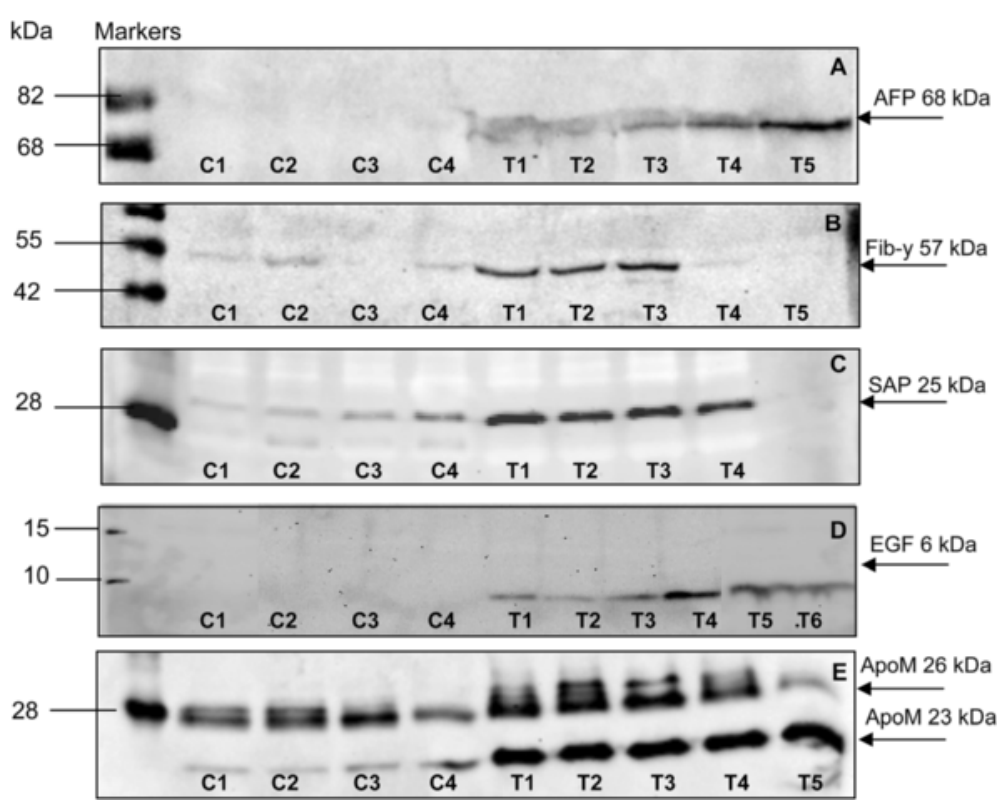

Figure 2 Western blotting of serum proteins in control and EGF transgenic mice. For the commonly regulated proteins in serum and tumours their regulation in liver tissue was confirmed by 2DE and MALDI-TOF/MS (see Table 1). Depicted are Western blots for serum proteins. Note, with the exception of EGF the regulated serum proteins were already reported in our earlier publication [7]. C 1-4=individual control animals, T 1-6=individual tumour bearing mice. (A) alpha-fetoprotein, (B) fibrinogen gamma, (C) serum amyloid component P, (D) epidermal growth factor, (E) and apolipoprotein $M$ which was identified in serum samples only.

ER-nucleus signalling pathway and response to ER oxidative stress as well as hypoxia, blood coagulation, developmental growth and regulation of programmed cell death.

\section{Cellular components and molecular functions}

As depicted in Figure 4B 76 significantly regulated proteins were mapped to 21 cellular components (see Additional file 7: Table S7), i.e. mitochondrial crista, matrix and inner membrane, endoplasmic reticulum lumen, early endosome and cytoplasmic membrane-bounded vesicle, chylomicron, very-low and high density lipoprotein particle, proteasome accessory complex, peroxisome, extracellular vesicular exosome and extracellular membrane-bounded organelle.

Furthermore, 75 significantly regulated proteins were mapped to 21 molecular functions (see Figure 4C) and included arginase activity, fructose-bisphosphate aldolase activity, hydrolase and oxidoreductase activity, acting on carbon-nitrogen (but not peptide) bonds, acting on aldehyde, $\mathrm{CH}-\mathrm{OH}$ group or oxo group of donors, NAD or NADP as acceptor as well as steroid dehydrogenase activity. In addition, phosphatidylcholine-sterol O-acyltransferase activator activity, cholesterol transporter activity, sterol transporter, antioxidant and lipid transporter activity as well as electron carrier and serine-type endopeptidase inhibitor activity were prominent functions. Finally, proteins functioning in metal ion and purine ribonuleoside triphosphate binding, lipoprotein particle receptor binding, chaperone and oxygen binding, binding of magnesium ion and NAD, protease and single-stranded DNA binding were observed as disease regulated (Additional file 8: Table S8).

\section{Pathway analysis of tumour proteins}

In all, 96 significantly regulated proteins were classified by the REACTOME, KEGG and WikiPathway databases, respectively. The different databases provided similar information with the majority of tumour proteins acting in 4 major metabolic pathways (see Figure 5 and information derived from ClueGO and CluePedia). For example, the proteins ALDOA, ALDOC, FBP1 and PKM function in glycolysis and gluconeogenesis whereas AKR1C6, ALDOA, ALDOC and FBP1 are part of the fructose and mannose metabolic pathway. Likewise, ATP5H and NDUFV1 are part of the oxidative phosphorylation pathway and MDH1 and PKM contribute to pyruvate metabolism. Similarly, the proteins AKR1C14, AKR1C18, AKR1C6, ALB, APOA1, APOA4, APOE, FDPS, GPX1, HACL1 and PLG take part in the metabolism of lipids, arachidonic acid and lipoproteins whereas the proteins AGMAT, ARG1, ARG2, BCKDHA, CKB, CPS1, HAAO and PHGDH are specified for arginine and proline metabolism. In the same manner the proteins GPX1, ITPA and NME1 contribute to the metabolism of nucleotides and related to this are the proteins ITPA, PKM and PSMC5 which are part of the purine metabolic pathway. Apart from these pathways a highly significant regulation of the blood coagulation cascade, 


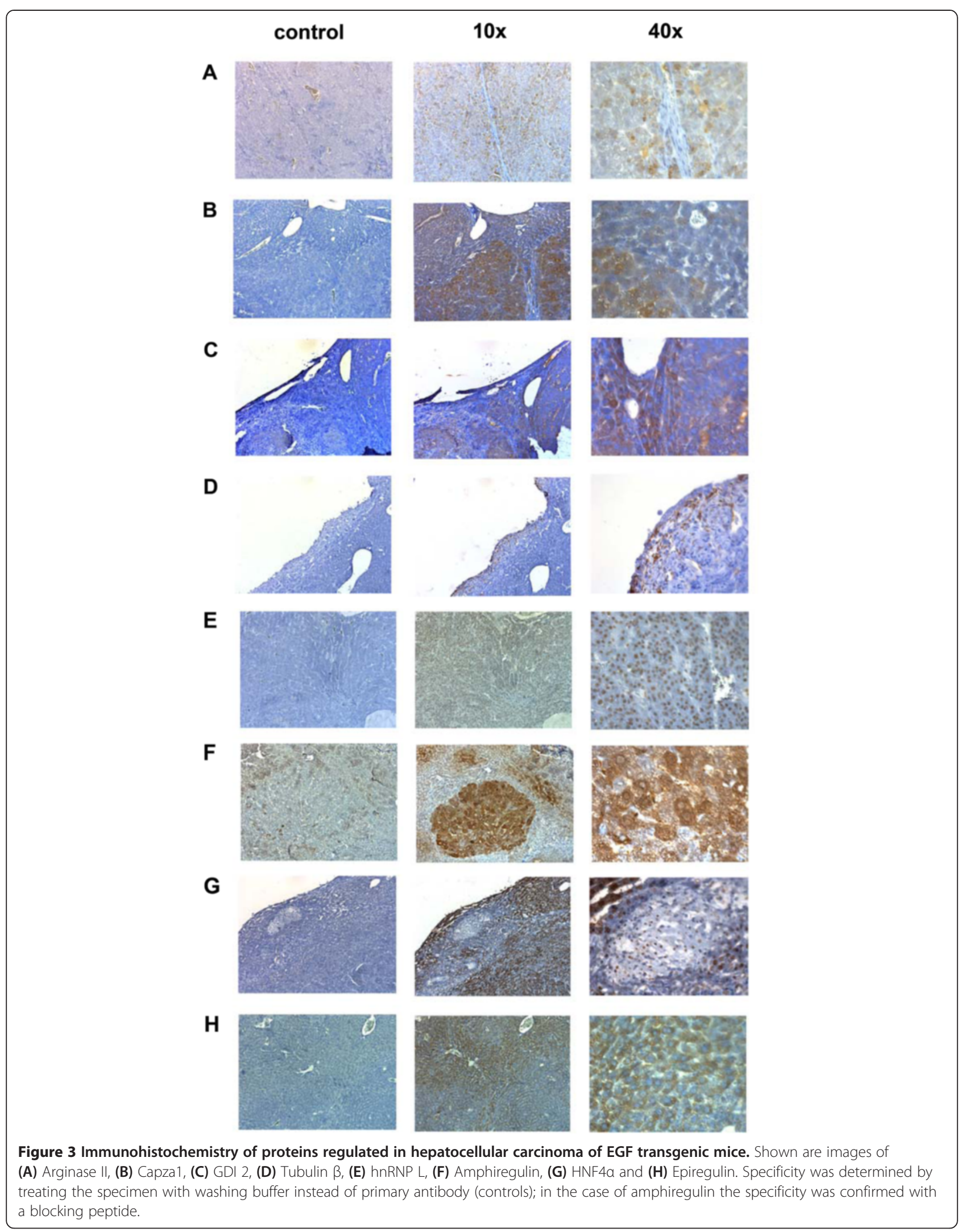


A
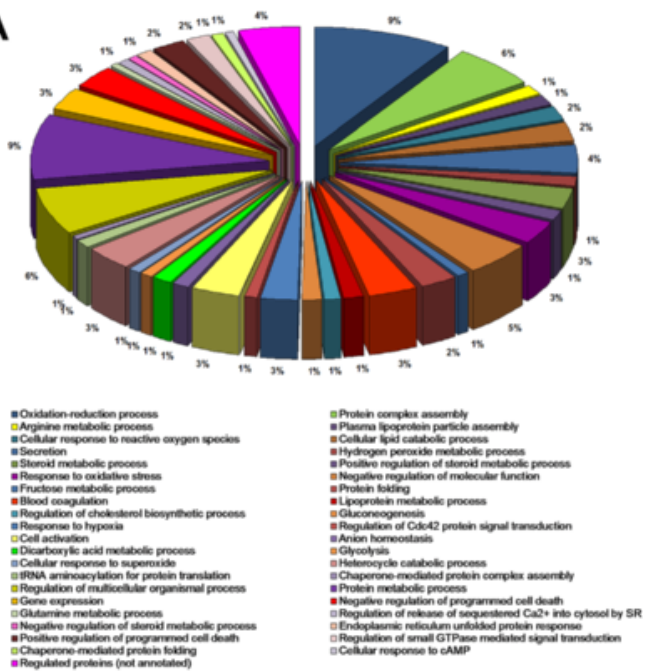

B
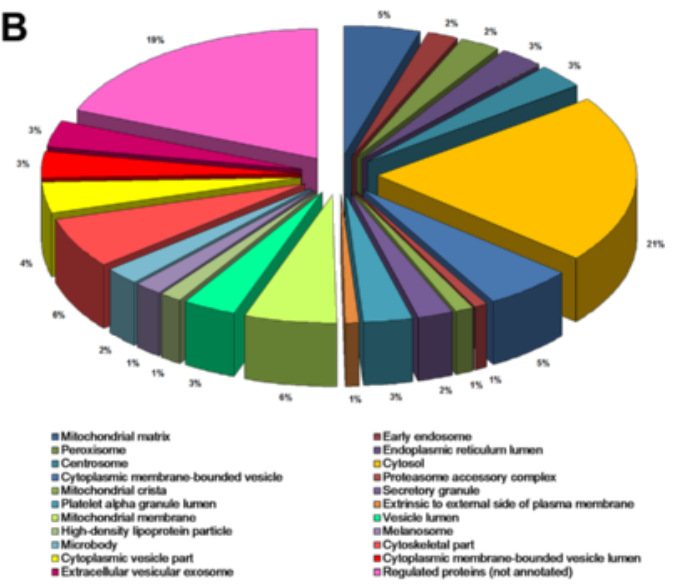

C
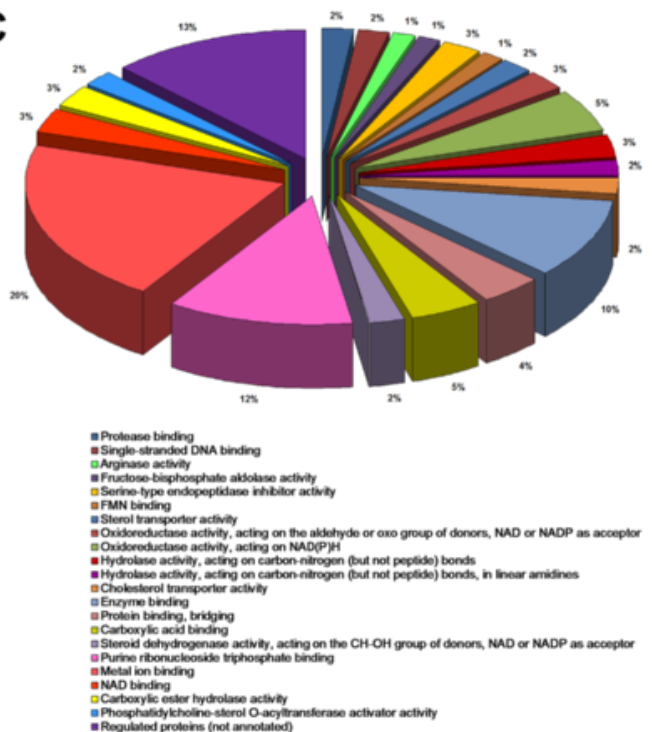

Figure 4 Significantly regulated proteins categorized by GO terms. (A) Biological process, (B) Cellular components, (C) Molecular functions. The piecharts depict the percentage of proteins involved in the various $\mathrm{GO}$ terms. platelet activation and fibrinolysis was observed as defined by the proteins CRK, FGA, FGB, FGG, PLG and SOD1 all of which were highly significantly regulated. Furthermore, tRNA aminoacylation (AARS, GARS and SARS), advanced glycosylation endproduct receptor signalling (ALB, CAPZA1 and LGALS3), peroxisome (ECH1, HACL1 and SOD1), protein processing in endoplasmic reticulum (GANAB, HYOU1 and PDIA4), proteasome (PSMC5 and PSMD11) and activation of chaperone genes by $\mathrm{XBP} 1(\mathrm{~S})$ and 'unfolded protein response' (HYOU1 and LMNA) are pathways significantly perturbed in liver cancer induced by EGF (see Additional file 9: Table S9 and Additional file 10: Table S10).

\section{Identification of master regulatory proteins}

Using the designated workflow of the GeneXplain platform (see Methods section) we searched for master regulatory proteins. The software is designed to identify molecules upstream of regulated tumour proteins to assist in the construction of molecular circuitries. After annotation of the input datasets the tool "Find master regulators in networks (GeneWays)" was used to identify key nodes amongst 54 proteins exclusively expressed in tumours (To). This revealed 24 upstream regulatory molecules. Among them five were selected for their link to the EGFR signalling pathway, i.e. PLAUR, FGFR1, PTBP1 and AGTRAP while the protein S100A1 was chosen for its importance in the PLAUR/EGFR network, (see Additional file 11: Figure S1A-E).

In Additional file 3: Table S3 and Additional file 12: Table S11, the tumour regulated proteins distributed amongst the selected master regulatory molecules are summarized.

In support of its biological significance the constructed networks were enriched with gene expression data from transgenic non-tumour and tumour tissues. Thus, the gene and protein data were merged and hybrid networks for each master regulatory protein were constructed. Subsequently, these were merged into one (see Figure 6) and the integrated hybrid network consisted of $n=82$ network proteins of which $n=20$ were tumour specific. In support, the genes coding for lmna, i.e. a component of the nuclear lamina that is frequently up-regulated in cancers and $m v p$ that codes for multidrug resistance were up-regulated (ur-T) whereas nme, a suppressor of metastasis was repressed in expression $(\mathrm{dr}-\mathrm{T})$. Likewise, the genes coding for igals3, i.e. a beta-galactoside-binding protein frequently overexpressed in cancers and $p c b p 1$ that is involved in transcription and functions as an inhibitor of invasion [65] were up-regulated in transgenic nontumour livers (ur-Tr-nT) whereas transcript expression of aars, a member of tRNA synthases and anaxa6, a calcium-dependent, phospholipid-binding protein with important roles in the tumour microenvironment and metastasis were repressed $(\mathrm{dr}-\mathrm{Tr}-\mathrm{nT})$. Finally, the entire network was enriched with expression data of 16 and 


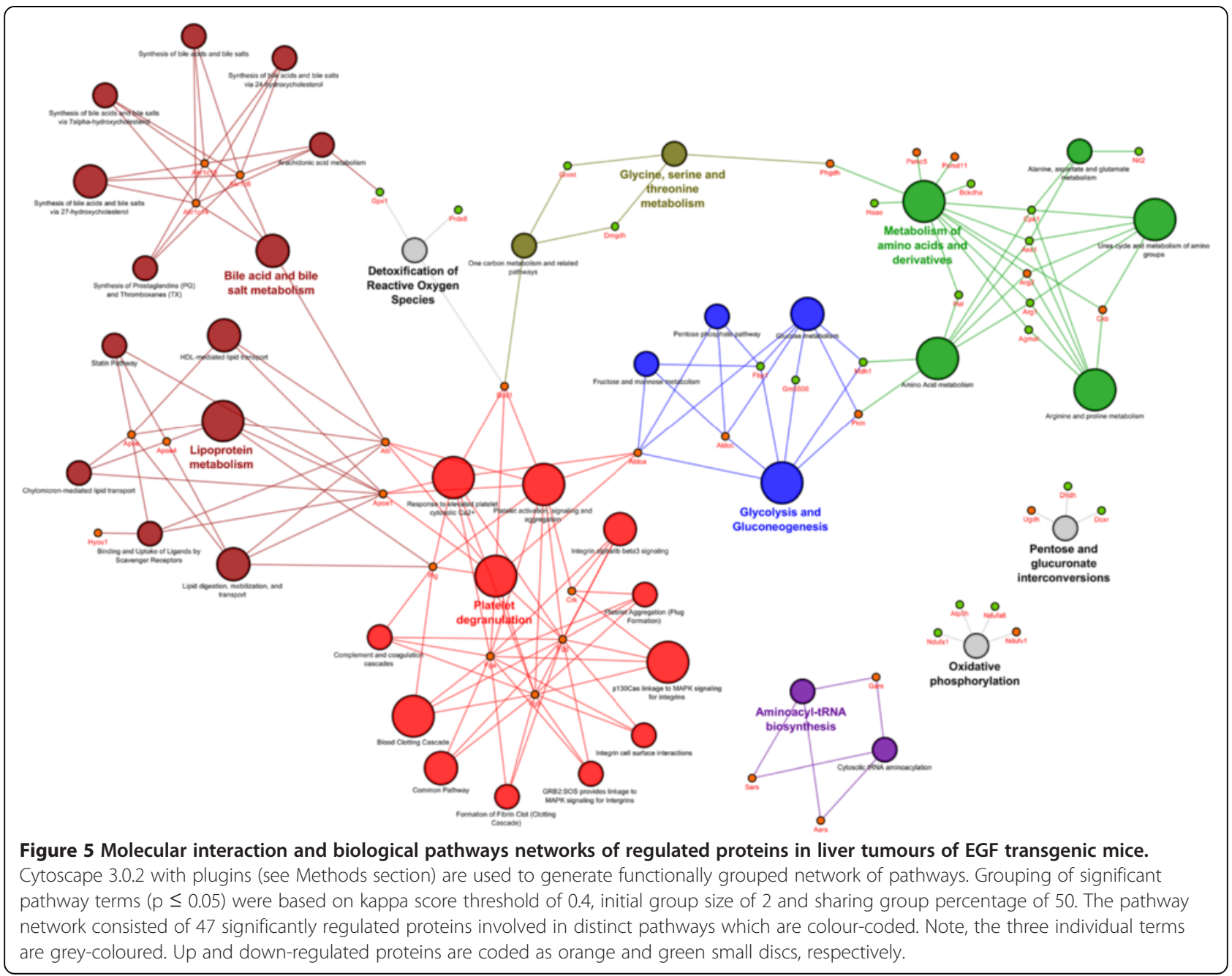

17 genes, respectively that were significantly regulated in tumour and non-tumour transgenic livers.

Next, we searched for master regulatory molecules by considering 82 regulated tumour proteins obtained from the comparison tumour specific or up- and down regulated as compared to healthy non-transgenic controls (To + UR + DR). This revealed 29 filtered (threshold radius of 10) upstream regulators. Among these 7 were selected as candidates because of their regulation in liver tumours and their link to EGFR signalling. Notably, in the constructed network all master regulators were significantly up-regulated and included PDIA4, APEH, PEBP1 and APOE while the protein expression of ARG1, FBP1 and HAAO was repressed (see Additional file 13: Figure S2A-G). Note, in the case of ARG1 transcript expression was equally repressed.

In Additional file 3: Table S3 and Additional file 12: Table S11 the tumour regulated proteins distributed amongst the selected master regulatory molecules are summarized.

In support of its biological significance the fused hybrid network was enriched for gene expression data derived from transgenic non-tumour and tumour tissues. Thus, the integrated hybrid network consisted of 34 out of 82 regulated proteins and gene expression calls evidenced 6 of the 27 up-regulated tumour (To + UR) proteins to be regulated at the transcript level as well whereas among the 7 down-regulated tumour proteins (DR) the gene $\arg 1$ was repressed in expression. Likewise, gene expression data from non-tumour transgenic livers evidenced 5 genes out of 27 networks partners to be increased in expression (ur-Tr-nT) and among the 7 down-regulated networks proteins the gene $p h b$ was repressed $(\mathrm{dr}-\mathrm{Tr}-\mathrm{nT})$. Thus, when the tumour gene expression data of the entire network was considered a total of 22 genes were regulated, of which 13 were up-regulated and 9 were repressed in expression, (see Figure 7).

\section{Protein interaction network}

Based on the information of the hybrid master regulatory network and in addition to other disease regulated proteins summarized in Table 1 (note, some of the proteins were not part of the networks) a total of $n=122$ disease 


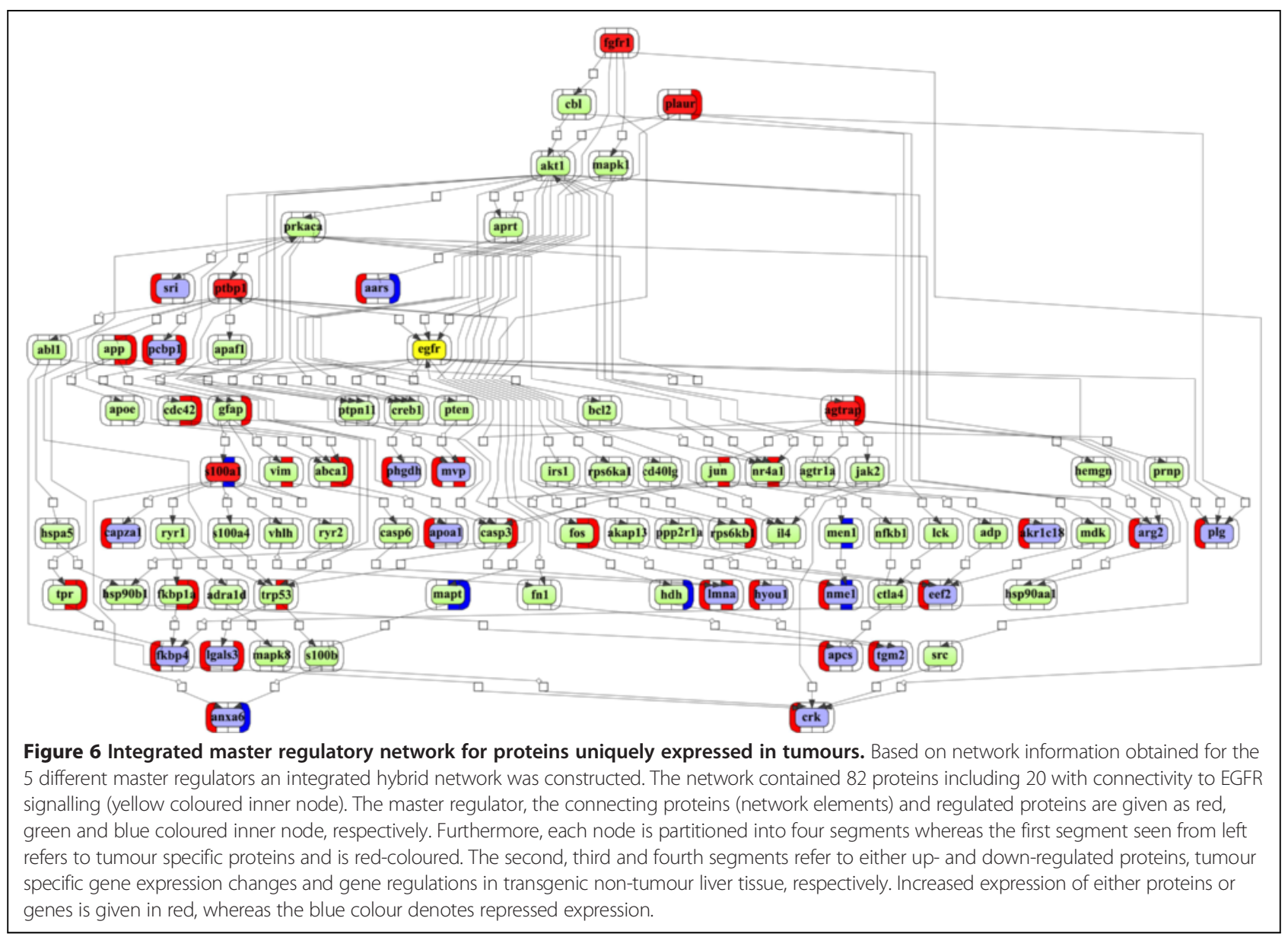

regulated proteins were considered for network construction. After filtering for non-connected proteins the STRING database informed on $\mathrm{n}=151$ protein-interactions of which $\mathrm{n}=76$ were disease regulated as identified in the present study. Among these 45, 24 and 7 were either up-, down- or not statistically significantly regulated. Furthermore, gene expression calls for 45 up-regulated proteins were supported by 5 up- and 4 down-regulated genes identified in tumours and 4 up- and 6 down-regulated genes in transgenic non-tumour livers. Likewise, gene expression calls for 24 down-regulated proteins were supported by 8 and 5 downregulated genes in tumours and transgenic non-tumour livers, respectively. Therefore, the entire network was supported by 14 induced and 17 repressed tumour specific gene expression changes and 16 up-regulated and 13 downregulated genes observed in transgenic non-tumour livers. As depicted in Figure 8 the proteins of the fusion network displayed functional associations via the EGF/EGFR network and included 69 out of 96 (72\%) significantly regulated tumour proteins with 6 out of 7 master regulators being connected to EGFR through the network's proteins (see Additional file 14: Table S12 for possible protein-protein interactions and related scores).

\section{Pathways mapping of fussed network proteins}

Of the 151 network proteins 109 could be mapped to distinct pathways. After removal of non-relevant terms such as Alzheimer disease a total of 94 proteins were mapped to 6 pathways with meaningful associations (see Figure 9) and consisted of 'platelet activation, signalling and aggregation (platelet degranulation)', 'lipoprotein metabolism', 'MAPK signalling pathway', 'glycolysis and gluconeogenesis', 'metabolism of amino acids and derivatives (arginine and proline metabolism)', 'apoptosis' and 'EGFR1 signalling pathway'. Additionally, a total of 2 and 3 tumour regulated proteins were mapped to the HIF-1 signalling and protein processing in endoplasmic reticulum pathways, respectively. The pathway mapping was also supported by gene expression data with 10 up- and 9 down-regulated genes in tumours and 9 up- and 6 downregulated genes in transgenic non-tumour livers. Note, two of the significantly regulated tumour proteins, i.e. CRK and PEBP1 are members of the EGFR1 signalling pathway with PEBP1 also functioning as a master regulator while the other regulated proteins are connected to EGFR signalling through cross-talk among the pathways (see Additional file 15: Table S13). 


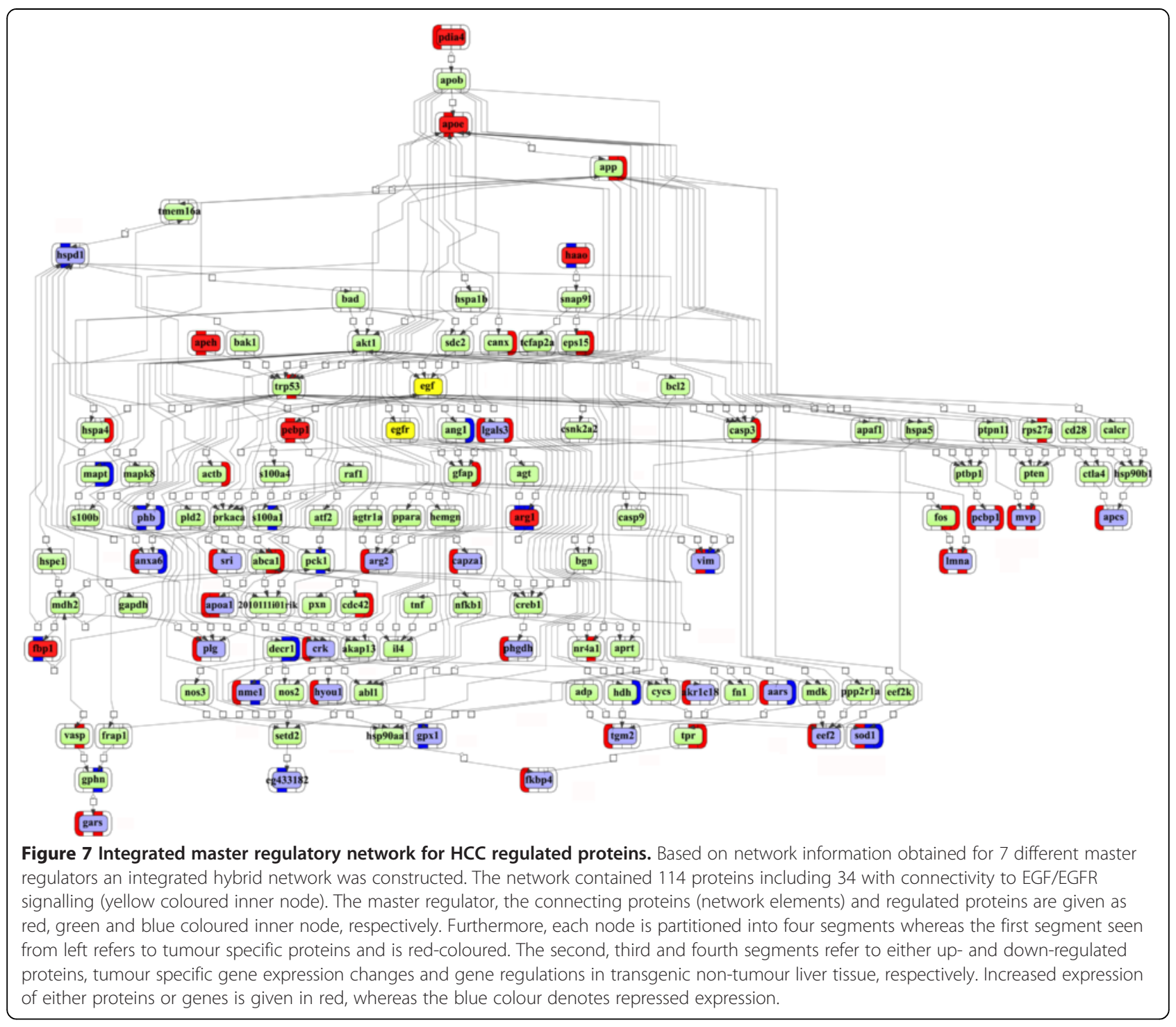

\section{Discussion}

Recent research into the molecular pathogenesis of HCC evidenced significant alterations in signalling pathways. Given the fact that the epidermal growth factor is an important mitogen for hepatocytes we were particularly interested in investigating the consequences of its targeted overexpression in the liver. In our previous study we employed chromatin immunoprecipitation followed by cloning and sequencing of DNA to search for tumour associated gene regulations targeted by novel HNF4alpha P1 and P2 promoter-driven isoforms. This identified EGF-receptor substrate (EPS15R) and EPS15 as regulated by the P2 promoter-driven HNF4alpha splice variant in mouse and human HCC. A molecular circuitry was proposed whereby EPS15 and EPS15R mediate internalization of activated EGFR to stimulate receptor recycling, therefore responding to mitogenic signalling of EGF [66]. In the present study disease proteomics was performed to further investigate the role of EGF in liver cancer. This identified 122 regulated proteins of which 37 are novel and have not been reported so far.

\section{Extra-cellular space and secreted proteins}

A total of 63 proteins were significantly up-regulated (Table 1). Among these 18 were extra-cellular or secreted proteins and included albumin and isoforms of it, apolipoproteins (ApoE, ApoA4 and ApoAI), $\alpha-, \beta-, \gamma-$ fibrinogen, plasminogen as well as interleukin 1 receptor antagonist (IL-1RA). Note, an isoform of ApoA1 was already proposed as serum marker of HCC [67] and based on IHC staining IL-1RA expression was confirmed in about $70 \%$ of mouse liver adenoma and carcinoma cases; however preneoplastic foci as well as normal hepatocytes surrounding the lesions were negative. Furthermore, RTPCR analysis confirmed mouse hepatic tumours to contain both secreted and intracellular forms of IL-1ra [51] and 


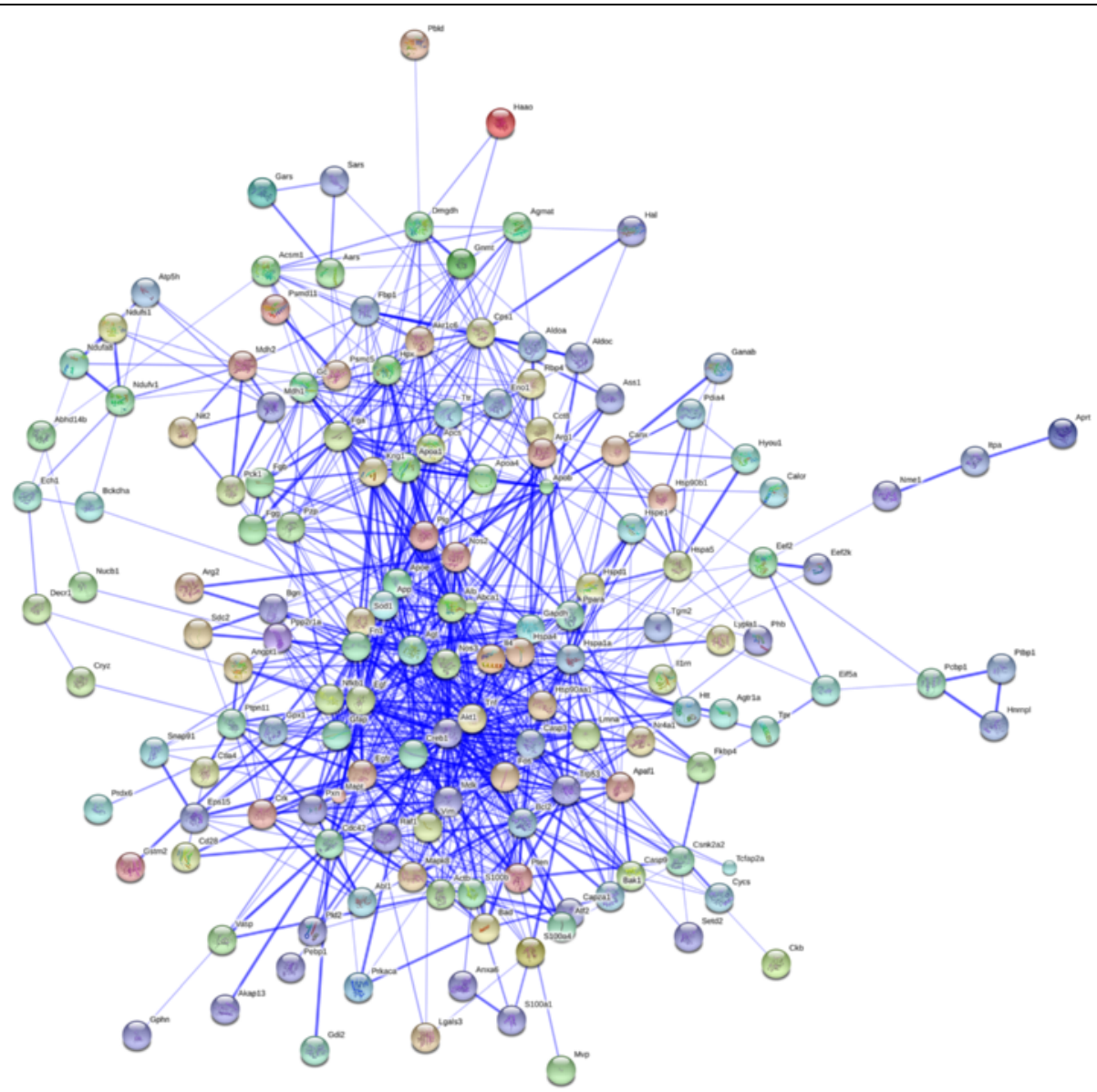

Figure 8 STRING protein-protein interaction network. The network consisted of 69 statistically significantly up- and down-regulated proteins and 7 regulated proteins which failed to reach statistical significance. This STRING protein-protein network is a confidence view and a required default confidence score of 0.4 was set. The protein network depicts interaction of regulated proteins including master regulators connected to EGFR signalling.

serum levels of IL-1ra were monitored to assess therapeutic efficacy of radiofrequency ablation in HCC patients [68].

\section{Mitochondrial proteins}

An important finding of the present study is the statistically significant regulation of 20 mitochondria associated proteins of which 13 were repressed while 7 were upregulated. Similar results were reported by Chignard and Wei Sun with mitochondrial proteins being the second largest proportion of regulated proteins in human viral HCC [15,69]. Among the repressed proteins were NADH dehydrogenase (ubiquinone) 1 alpha subcomplex 8 and prohibitin, a mitochondrial chaperone. This protein, when deleted (prohibitin KO mice) induced fibrosis, bile duct metaplasia, liver dysplasia and eventually multifocal HCC. However, its overexpression in tumour cell lines inhibited cell proliferation to demonstrate tumour suppressor function [70]. Likewise, glutathione peroxidase 1 (response to oxidative stress) and argininosuccinate synthetase 1 (ASS, urea cycle) were repressed. Note, ASS is the first of two enzymes to convert citrulline to arginine and this pathway allows cells to synthesize arginine from citrulline to function in NO production, ammonia detoxification and synthesis of polyamines. Several reports suggest ASS deficiency to be common in tumour cell lines [25-30], and the present study confirms ASS expression to be confined to healthy non-transgenic control liver, but ASS was absent in tumour tissue extracts (see Table 1). Ablation of ASS in diverse tumours suggests a tumour suppressor function and the fact that forced expression of ASS in osteosarcoma cell lines suppresses growth adds weight to this notion [71].

Another example of tumour specific ablation of proteins refers to glycine $\mathrm{N}$-methyltransferase (GNMT). The enzyme catalyzes the transfer of a methyl group from $\mathrm{S}$-adenosylmethionine (SAM) to glycine thereby generating S-adenosylhomocysteine and N-methylglycine. This protein was completely downregulated in liver tumours. GNMT is known to play a role in the maintenance of genetic stability $[44,72]$, and a novel tumour suppressor function 


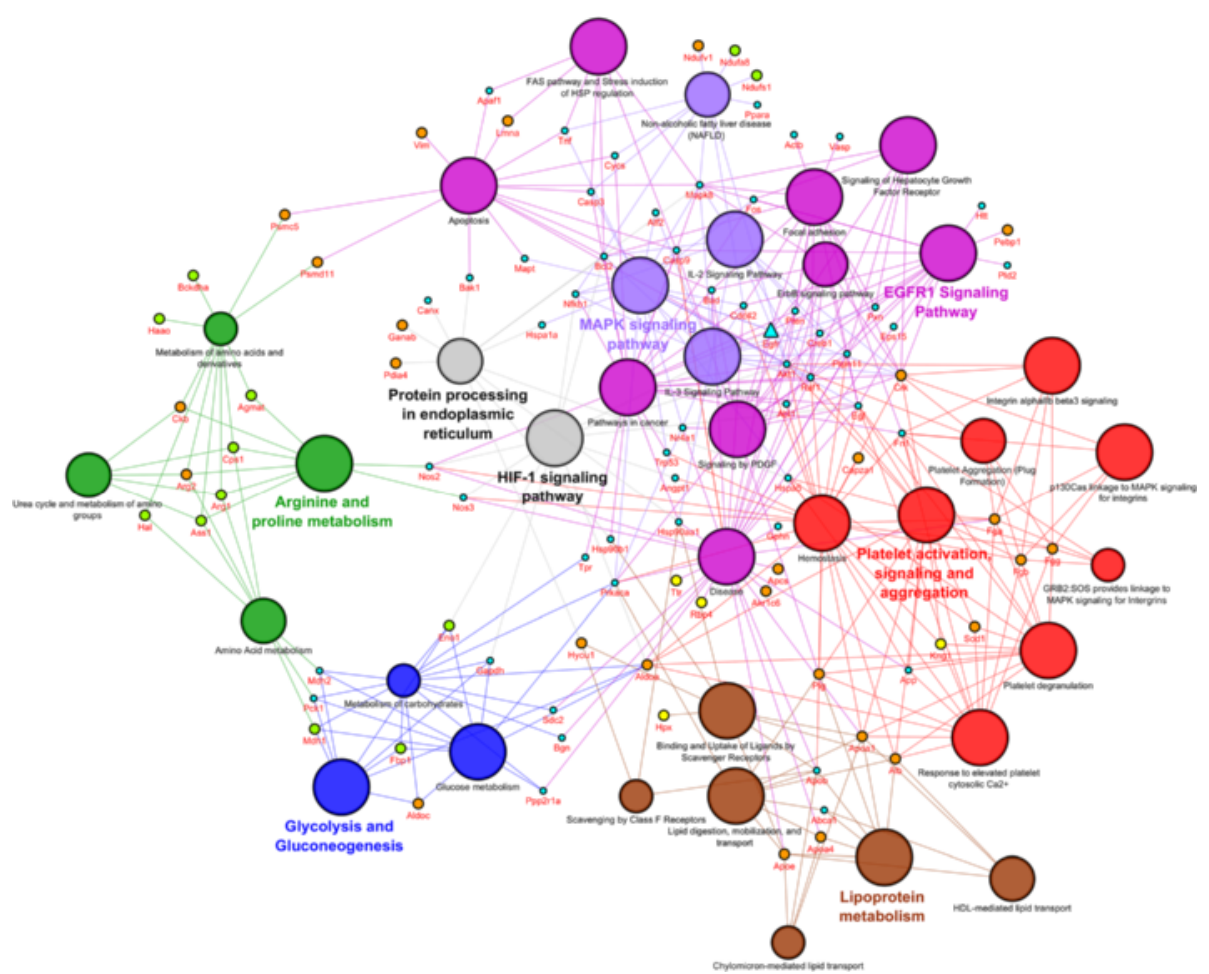

Figure 9 Pathways mapping of fussed network proteins. Cytoscape 3.0.2 with plugins (see Methods section) are used to generate functionally grouped network of pathways. Grouping of significant pathway terms ( $p \leq 0.05)$ were based on kappa score threshold of 0.4 , initial group size of 2 and sharing group percentage of 50 . The pathway network consisted of 35 significantly and 7 non-significantly regulated proteins involved in distinct pathways which are colour-coded. Note, the two individual terms are grey-coloured. Up and down-regulated proteins are coded as orange and green small discs, respectively. Up- and down-regulated as well as non-significantly regulated proteins and connecting proteins of the network are given as orange, green, yellow and blue coloured discs, respectively. The network depicts protein-protein interactions in liver tumours of EGFR transgenic mice and their relation to various pathways under the influence of EGFR signalling. EGFR is highlighted as blue triangle in this network.

was recently reported that is independent of its catalytic activity but does require its nuclear localization [73].

\section{Newly identified disease-regulated proteins}

Several of the proteins listed in Table 1 were already reported for their tumour specific regulation while proteins so far unknown for their regulations in $\mathrm{HCC}$, are marked with an asterisk (Table 1). These function in diverse biological processes including metabolism, translation and signalling.

Specifically, changes in carbohydrate metabolism are commonly observed in tumours where energy production relies on glycolysis rather than mitochondrial oxidative phosphorylation. In the present study induced expression of several glycolytic enzymes was observed, most notable [1] pyruvate kinase 3 that catalyzes the transfer of a phosphate group from phosphoenolpyruvate to ADP and was shown to be a target of mi-RNA122 in HCC [2,74] aldolase, an enzyme that converts fructose 1,6-bisphosphate into dihydroxyacetone phosphate (DHAP) and glyceraldehyde 3-phosphate and was reported to be a sensitive marker for benign and malignant liver disease [75] and [3] alpha glucosidase 2, a hydrolase that cleaves glycosidic bonds with the release of alpha glucose from carbohydrates.
Further important findings include the tumour specific expression of alanyl-, glycyl- and seryl-tRNA synthetases which catalyze the transfer of specific amino acids to tRNA, as well as regulation of eukaryotic translation elongation factor 2 and Poly $(\mathrm{rC})$ protein 2 that binds to oligo dC. Note, knowledge on the role of aminoacyl-tRNA synthetases in cancer is just emerging [76] and through the use of a lentiviral mediated shRNA vector, a link between aminoacyl-tRNA synthetases [AARS]-interacting multifunctional protein 2 (AIMP2) and repressed EGFR signalling was established that resulted in repressed glucose uptake [77]. We also observed induced expression of heterogeneous ribonucleoprotein (hnRNP) that takes on diverse functions in the processing of mRNA. Its expression was reported to be increased in serum of HCC patients In contrast, proteins involved in the synthesis and degradation of cholesterol, lipids, steroids and fatty acid were in part oppositely regulated and included induced expression of the aldo-keto reductase family 1 . Regulation of this protein has been reported for lung and pancreatic cancers [78], and gene silencing of aldo-keto reductase family 1 B10 resulted in growth inhibition of colorectal cancer cells that might be of therapeutic utility [79]. The repressed expression of 
certain proteins may also be considered as an adaptive response and includes the enzyme enoyl coenzyme A hydratase 1. Its activity was shown to contribute to lymphatic spread of liver tumours as was evidenced in gene silencing studies [80]. Likewise, we observed repressed expression of dihydrodiol dehydrogenase in tumours. This enzyme plays an important role in the metabolism of steroids that leads to inactivation of circulating androgens, progestins and glucocorticoids and was repeatedly reported to be overexpressed in non-small cell lung cancer. Amongst patients with high DHD expression the incidence of early tumour recurrence and distant metastasis is significantly higher and patients are highly resistant to chemo and radiotherapy [81].

Intriguingly, complete ablation of mitochondrial butyryl coenzyme A synthetase 1, a GTP-dependent lipoateactivating enzyme was observed in tumours of EGF transgenic mice. Little is known about the possible link between butyrate metabolism and liver cancer. However, butyrate is well known to inhibit proliferation of human colon carcinoma cells in an epigenetic manner that involves histone acetylation [82]. Note, it was recently reported that due to the Warburg effect butyrate-mediated histone acetylation and cell proliferation is dictated [83]. Several lines of evidence therefore suggest butyrate to act as a cytosolic sensor for histone acteylation and when transformed to intermediates by butyryl coenzyme A synthetase is unable to escape the mitochondria.

Moreover, we observed a highly significant repression of 2-hydroxyphytanoyl-CoA-lyase. This peroxisomal thiamine pyrophosphate-dependent enzyme is rate limiting in the breakdown of 2-hydroxy fatty acids. The biological role of 2-hydroxy fatty acids has only recently become apparent [84] and cumulative evidence suggests intermediates of energy metabolism to specifically activate G-protein coupled receptors which are now classified as hydroxy carboxylic acid receptors (HCA1-3). The HCA2 receptor is involved in a complex negative feed-back loop whereby ketone bodies derived from fatty acid oxidation are sensed by HCA2 via the activity of 3-hydroxybutyrate that leads to inhibition of lipolysis and to restriction of further fatty acid supply. In this way triglyceride use is diverted and energy demands for tumour growth are met more efficiently. Specifically, during rapid tumour growth and the herewith associated ischemia the yield of high energy bonds (ATP) from glucose oxidation is about twice that of fatty acid oxidation. Our observation that proteins involved in the $B$-oxidation of fatty acids were either repressed or unchanged agrees well with this principle (see also discussion below).

The reduced expression of lysophosphopholipase signifies an adaptive response; it catalyses the production of lysophosphatidic acid, i.e. a second messenger known to contribute to tumour cell motility, survival and proliferation [85]. Additionally, the repressed expression of mitochondrial acyl-CoA thioesterase 1 in liver tumours which hydrolyzes acyl-CoAs to free fatty acids and coenzyme A, will influence the supply of ligands for nuclear receptors and the regulation of fatty acid oxidation in mitochondria and peroxisomes. Equally, the regulation of farnesyl diphosphate synthetase, i.e. a key enzyme in the isoprenoid biosynthetic pathway is highly interesting and this enzyme is explored as a drug target of bisphosphonates to treat tumour growth [86]. It's up-regulation in colon cancers was reported [39]. In the present study repressed expression of the ribosom-compononent RPS12 and enzymes of amino acid metabolism like branched chain ketoacid dehydrogenase E1 as well as dimethyl glycine dehydrogease was observed. Conversely, expression of the proteasome $26 \mathrm{~S}$ ATPase subunit 5 (p45/SUG) and its non-ATPase regulatory subunit 11 (PSMD11) was confined to tumour tissues (see Table 1); the latter subunit is known to display high activity in embryonic stem cells. This multicomplex molecular machinery degrades intracellular proteins marked up by ubiquitin chains. PSMD11 was reported to be up-regulated in breast cancer cells [87].

Enhanced expression of cytoskeletal proteins such as tubulin $\beta 5$ and CAPZA1 was also confirmed by IHC staining (see Figure 3). Differences in the localization of these proteins were obvious with tubulin $ß 5$ expression being primarily associated with cells proximal to the liver capsule, whereas expression of capping protein Zline $\alpha 1$ (CAPZA1) was strongly associated with tumour foci and this protein is known to play a pivotal role in cytoskeletal networks to support cell mobility, invasion and metastasis. Additionally, GDI2, a protein functioning in the cycling of Rab GTPases and arginase II, i.e. a non-liver isoform of the urea cycle were up-regulated in tumours of EGF transgenic mice (see Figure 3). Regulation of arginase II was observed in various malignancies including lung cancer [88]. Besides, the actin-binding protein LASP1 was uniquely expressed in tumours and is also up-regulated in breast cancer [89] to possibly support migration of cancer cells [90]. Furthermore, PDIA4, a disulfide bond isomerase and master regulator of the constructed networks (see below) was up-regulated as was kininogen that is part of the blood coagulation system and functions as a precursor of kinin. Conversely, the serinproteinase inhibitor Serpinbla was repressed in expression to possible limited immunological responses in tumour growth and to influence inflammatory cytokine production by infiltrating monocytes [91].

The significant regulation of the calcium binding protein sorcin and nucleobindin 1 are further highly interesting results. Sorcin is associated with multidrug-resistance in human leukemia cells [92] and nucleobindin 1 is evaluated as a biomarker of colon cancer [93]. In EGF induced liver tumours transthyretin was also up-regulated. This protein is involved in the transport of thyroid hormones and was reported to be aberrantly regulated in thyroid cancer [94]. 
Among the newly identified proteins is v-crk sarcoma virus CT10. This oncoprotein interacts with several tyrosinephosphorylated proteins and is part of the intracellular signalling cascades notably the phosphoinositide 3-kinase (PI3K)/AKT pathway [95]. Likewise, regulation of the $170 \mathrm{kDa}$ glucose-regulated protein GRP170 is of great importance. This lumenal endoplasmic reticulum plays a role in immunoglobulin folding as was confirmed by coimmunoprecipitation in four different B cell hybridoma cell lines [11]. In our previous study several immunoglobulins were found to be either repressed or absent in serum of EGF tumour bearing mice and this was particularly obvious for the Ig $\mathrm{K}$ and $\mathrm{L}$ classes [7]. It remains to be determined whether repression of immunoglobulins can be attributed to aberrant GRP170 activity.

A summary of the biological functions in addition to their previous reported tumour association is given in Additional file 16: Table S14 while the regulation of genes coding for newly identified proteins and of genes coding for commonly regulated proteins in liver tumours and serum of EGF2B-transgenic mice is given in Additional file 17: Table S15 and Additional file 18: Table S16.

\section{Master regulatory networks}

Initially the network construction was based on proteins exclusively expressed in tumours and by selecting master regulatory proteins linked to EGFR signalling. Thereafter, a fused hybrid network was developed in which tumour specific proteins were part of it. Subsequently, the search was extended to all significantly regulated proteins (Table 1). This revealed 7 master regulatory proteins and its associated networks and encompassed 114 proteins of which 34 were disease regulated. Eventually a fused network was developed; however not all disease regulated proteins are part of it. The performed pathway mapping over fused networks (see STRING analysis) defined protein interactions and grouped 76 disease regulated proteins into 6 distinct pathways of which platelet activation, signalling and aggregation is a major one (see Figure 8).

Specifically, the glycoprotein fibrinogen is a multimeric protein and consists of $\alpha, \beta$ and y subunits. It is synthesized by hepatocytes and an essential blood coagulation factor with all polypeptide chains being highly regulated in tumours of EGF transgenic mice. Note, an association between coagulation factors and malignancies was established whereby fibrinogen functions as an extracellular matrix protein to interact with integrin receptors in the control of cell proliferation and cell migration [96]. Accordingly, induced gene expression of the integrin receptors Itgb1, Itga3 and Itgav was observed in EGF induced liver tumours. In cancer progression a regulatory loop between fibrinogen, platelets and tumour cells has been determined that is activated by platelet cytosolic $\mathrm{Ca} 2+$. This second messenger induces integrin receptor complex formation through an association of platelet glycoprotein chains IIb and IIIa (CD41/CD61) thereby creating an active binding site for fibrinogen. An association of tumour regulated proteins with the regulatory loop was confirmed in STRING analysis (Figure 8) and fibrinogen was reported to be an important determinant for metastasis of circulating tumour cells [97]. It is therefore of no surprise that elevated blood fibrinogen is a poor prognostic factor. Haemostatic complications are commonly observed in cancer patients and future therapeutic strategies may focus on the hemostatic system by targeting tumour stroma. In this regard the tumour specific induction of plasminogen is of great importance. This zymogen [98] is converted to plasmin by urokinase (UPA), a serine protease which itself was unchanged; however, gene expression of its receptor was significantly up-regulated in transgenic non-tumour livers. One report suggests the urokinase receptor to prime cells for proliferation in response to EGF by promoting Tyr845 phosphorylation and Stat5b activation; nonetheless, this depended on intracellular c-Src levels [99].

Further studies established a link between induced expression of plasminogen activator, uPA receptor and plasminogen activator inhibitor type-1 (PAI-1) and invasiveness and metastasis of HCC [100,101]. Indeed, a fine balance exists between the plasminogen activating system and its inhibition by PAI-1 and PAI-2. Based on transcriptomic data a highly significant induction of PAI-I (up to 12-fold) in large tumours of EGF transgenic mice was observed [6]; consequently, the regulation of components of the plasminogen activating system may be considered as part of a strategy to degrade extracellular matrix thereby facilitating invasion and metastasis [102,103].

To meet energy demands efficiently different sources are utilized and the induction of the proteins ALDOA, ALDOC, ENO1, PKM and FBP1 is testimony to an altered glycolytic and pentose phosphate pathway. However, with the exception of acyl-CoA thioesterase 2 that was below the limit of detection and functions in the hydrolysis of myristoyl- palmitoyl-, stearoyl- and arachidoyl-CoA esters the regulation of enzymes linked to fatty acid metabolism in mitochondria and peroxisomes was hardly observed.

In pursue of tumour growth and to sustain organelle and membrane biogenesis lipids are de novo synthesized and mobilized from stores and while the complex interaction of hepatic lipid and glucose metabolism in liver disease is the subject of intense research [104] the present study evidences significant regulation of several apolipoproteins, i.e. APOE, APOA1, APOA4 and isoforms of albumin. Apart from lipid transport apolipoproteins play a wider role in cancers and are known to interact with diverse receptors to elicit cellular events as demonstrated for APOE to cause sustained proliferation and survival of cancer cells [105]. 
A further group of highly regulated proteins are aldoketo reductases. Their quantitative evaluation in different hepatocellular carcinoma (HCC) cell lines was recently reported [106]. This superfamily of proteins comprises NAD $(\mathrm{P})(\mathrm{H})$-dependent enzymes which catalyze oxidoreduction of a variety of prostaglandins, steroids and toxic aldehydes. Their involvement in tumorigenesis is supported by several studies and they are explored as drug targets to overcome chemoresistance. In the present study the aldo-keto reductases AKR1C14, AKR1C18 and AKR1C6 were uniquely expressed in tumours, however glutathione peroxidase 1 was repressed to $30 \%$ of healthy control livers to possibly support HIF-1 signalling. Indeed, the redox state and therefore glutathione participates in the hypoxic induction of HIF-1 [107], and two proteins of the glycolytic pathway, i.e. ALDOA1 and ENO1, which respond to HIF-1 signalling, were regulated. Moreover, glutathione peroxidase 1 was shifted in the gel as shown in Figure 1 panel G III as a result of post translational modifications that most likely involved c-Abl and Arg kinase activity at Tyr 96 of GPX1 [108]. Likewise, the genes coding for Aldo1 and Eno3 were significantly up-regulated in EGF induced liver tumours.

A complex interaction exists between EGFR and RAGE signalling. This receptor for advanced glycation end-products is a member of the immunoglobulin family of cell surface molecules and was reported to significantly influence hepatic tumour growth in murine models of colorectal carcinoma [109]. There is strong evidence for RAGE to promote cancer growth upon ligand dependent activation and several proteins of the S100 family bind to the extracellular domain of RAGE [110,111]. It is of considerable importance that gene expression of S100a4 and S100a11 was up to 34-fold induced in tumours of EGF transgenic mice, however expression of S100a1 was repressed. Likewise the tumour specific expression of the RAGE binding proteins lectin, galactoside-binding, soluble, 3 and CAPZA1 in tumours of EGF transgenic mice is highly suggestive for a sustained crosstalk between RAGE and EGFR [112]. Although the precise mechanism by which $\mathrm{S} 100$ proteins stimulate EGFR signalling remains to be elucidated binding of S100A4 to EGF and to other EGFR ligands was reported to possibly facilitate interaction with the receptor [113]. Similarly, the binding of S100A8/A9 to RAGE was shown to promote migration and invasion of human breast cancer cells through actin polymerization and epithelial-mesenchymal transition [114]. Conversely, advanced glycation endproduct (AGE) receptor 1 suppressed oxidant stress-dependent signalling via the EGFR and Shc/Grb2/Ras pathway [115].

As depicted in Figure 5 the amino acid metabolism was another distinct pathway to which several of the regulated proteins could be mapped to. Note, the tumour specific regulations of arginine 1 and 2 as well as the regulation of subunits of the proteasome 26S ATPase (PSMC5 and
PSMD11) were already discussed (see above). In the following additional proteins regulated in this pathway are briefly summarized.

Specifically, 3-hydroxyanthranilate-3,4-dioxygenase (Haao) catalyzes oxidation of 3-hydroxyanthranilate to quinolinate and this intermediate functions as a precursor in NAD and pyridine biosynthetic pathways. Expression of Haao was significantly repressed in tumours of EGF transgenic mice and hypermethylation of the coding gene was observed in ovarian cancer [116]. Due to the fact that Haao is significantly repressed at the gene and protein level in at least two different tumour entities (ovarian and liver cancer) the protein may function as a tumour suppressor that appears to be repressed by an epigenetic mechanism.

A significant finding is the tumour specific expression of 3- phosphoglycerate- dehydrogenase which catalyses the production of 3-phosphoglycerate. This intermediate of glycolysis is an essential precursor of the serine biosynthetic pathway. Importantly, a recent metabolomic study evidenced 3-phosphoglycerate to be diverted into serine and glycine metabolism and repressed expression of 3-phosphoglyceratedehydrogenase resulted in impaired tumour cell proliferation [117]. In support of tumour growth the diversion of intermediate of glycolysis affects protein, membrane lipid and nucleotide synthesis.

Moreover, the observed induction of creatine kinase in tumours of EGF transgenic mice creates a circuitry for cellular energy homeostasis in conditions of high metabolic demands [118]. The enzyme catalyses the reversible transfer of phosphate from phosphocreatine to ADP to yield ATP and creatine. Its induction has been observed in many cancers including liver cancer cell lines $[119,120]$ and a further study suggested a possible interplay between p53 mutations, HCC, CK expression with growth-inhibitory effects of cyclocreatine in HCC [121].

While the rationale of tumour cells in embarking on abnormal metabolism had already been discussed (see above) the finding that agmatine ureohydrolase was strongly repressed in EGF induced liver tumours to about $10 \%$ of non-transgenic healthy livers is of great importance. This enzyme hydrolyzes agmatine (= decarboxylated arginine) to form putrescine and urea and repression of the enzyme will significantly increase agmatine tissue concentration to influence diverse cellular control mechanisms. Importantly, in the study of Battaglia and coworkers [122] $1 \mathrm{mM}$ agmatine induced large amounts of superoxide production in rat liver mitochondria; however, it did not affect mitochondrial respiration or redox levels of thiols and glutathione. Furthermore, ATP synthesis remained normal and prevented $\mathrm{Ca}(2+)$-induced mitochondrial permeability transition in the presence of phosphate to suggest an intriguing regulatory loop whereby $\mathrm{H} 2 \mathrm{O} 2$ induces hypoxia 
signalling that is linked to abberant metabolism, nonetheless by selecting interconnected physiological pathways tumour cells are equipped to avoid programmed cell death $[122,123]$. Thus, arginine deprivation is evaluated for its utility in cancer therapy [124].

A further enzyme repressed to $20 \%$ of healthy nontransgenic liver is carbamoyl phosphate synthetase 1 (CPS1), i.e. a liver specific ligase to function in ammonia detoxification. It is perplexing that tumour cells disable such an important pathway of the urea cycle. However, a recent study demonstrated DNA hypermethylation as a key mechanism of silencing CPS1 gene expression in human HCC. Note, forced expression of CPS1 induced cell proliferation and the observed repression in human HCC may simply be the result of genomic instability as was observed in tumour cells [125].

\section{Conclusion}

The present study identified novel disease regulated proteins induced by overexpression of EGF to provide new insight into the complex signalling events in HCC. Six major pathways perturbed by EGFR hyperactivity were identified and several of the regulated proteins are interesting drug target candidates and this includes tumour specific expression of kinases as well as proteins involved in aberrant metabolism. An identification of commonly regulated proteins in tumour and sera will be of great utility in the development of biomarkers to monitor disease progression and responses to therapy.

\section{Additional data files}

The following additional data are available with the online version of this paper.

\section{Additional files}

Additional file 1: Table S1. Antibodies and dilutions used to study disease regulation by immunohistochemistry.

Additional file 2: Table S2. Statistics and selection criteria for functional grouping of pathways terms of disease regulated proteins. A hypergeometric test followed by bonferroni correction was used with $p$-value $\leq 0.05$. For grouping of pathway terms, the kappa score threshold was set to 0.4 .

Additional file 3: Table S3. Different master regulators and associated network for proteins expressed in tumours only (To) or significantly regulated when compared to healthy liver of non-transgenic control animals $(T+U R+D R)$.

Additional file 4: Table S4. Comparison of disease regulated proteins in mouse and human HCC. Data were taken from 'The Human Protein Atlas' database.

Additional file 5: Table S5. Comparison of transcriptomic and proteomic data. This comparison revealed 19 significantly regulated genes of which 15 are regulated in common whereas for 4 genes transcript expression was opposite to that of the coded proteins.

Additional file 6: Table S6. Biological processes ontology for significantly regulated proteins.
Additional file 7: Table S7. Cellular component ontology for significantly regulated proteins.

Additional file 8: Table S8. Molecular function ontology for significantly regulated proteins.

Additional file 9: Table S9. Biological pathways and their cluster. Cytoscape 3.0.2 with plugins (ClueGO and CluePedia) were used to generate functionally grouped network of pathways based on REACTOME, KEGG and WikiPathways databases. The grouping of significant pathway terms ( $p \leq 0.05$ ) is based on a kappa score of 0.4 , initial group size of 2 and sharing group percentage of 50 .

Additional file 10: Table S10. Biological pathways information based each significantly regulated protein (To $+U R+D R)$. This table depicts pathway terms of nearly $80 \%$ of regulated proteins (To $+U R+D R$ ) and are taken from REACTOME and KEGG databases.

Additional file 11: Figure S1. Master regulatory networks for proteins uniquely expressed in tumours with link to EGFR signalling: (A) The PLAUR network consists of 44 proteins of which 20 are tumour-specifically regulated, (B) the FGFR1 consists of 41 proteins of which 18 are tumour-specifically regulated, (C) the PTBP1 network consists of 44 proteins of which 18 are tumour-specifically regulated, (D) the AGTRAP network consists of 43 proteins of which 19 are tumour-specifically regulated and (E) the S100A1 network consists of 38 protein of which 16 are tumour-specifically regulated. Note all networks display connectivity to EGFR signalling (yellow coloured inner node) and in the case of the S100A1 master regulatory protein EGFR s

ignalling is via the PLAUR/EGFR network.The master regulator, the connecting proteins (network elements) and regulated proteins are given as red, green and blue coloured inner node, respectively. Furthermore, each node is partioned into four segments whereas the first segment seen from left refers to tumour specific proteins and is red-coloured. The second, third and fourth segments refer to either up- and down-regulated proteins, tumour specific gene expression changes and gene regulations in transgenic non-tumour liver tissue, respectively. Increased expression of either proteins or genes is given in red, whereas the blue colour denotes repressed expression.

Additional file 12: Table S11. Integrated hybrid network with master regulator information for proteins expressed in tumours only (To) and significantly regulated proteins when compared to heathy liver of non-transgenic control animals ( $T+U R+D R)$.

Additional file 13: Figure S2. Master regulatory networks for regulated proteins with link to EGFR signalling: (A) The PDIA4 network consists of 68 proteins including 32 significantly regulated proteins, (B) the APEH network consists of 68 proteins including 32 significantly regulated proteins, (C) the PEBP1 network consists of 63 proteins including 31 significantly regulated proteins, (D) the APOE network consists of 66 proteins including 31 significantly regulated proteins, (E) the ARG1 network consists of 67 proteins including 31 significantly regulated proteins, (F) the FBP1 network consists of 69 proteins including 31 significantly regulated proteins, $(\mathrm{G})$ the HAAO network consists of 66 proteins including 32 significantly regulated proteins. Note, all networks display connectivity to EGF protein (yellow coloured inner node). The master regulator, the connecting proteins (network elements) and regulated proteins are given as red, green and blue coloured inner node, respectively. Furthermore, each node is partioned into four segments whereas the first segment seen from left refers to tumour specific proteins and is red-coloured. The second, third and fourth segments refer to either up- and down-regulated proteins, tumour specific gene expression changes and gene regulations in transgenic non-tumour liver tissue, respectively. Increased expression of either proteins or genes is given in red, whereas the blue colour denotes repressed expression.

Additional file 14: Table S12. Protein interaction information of the fused network. Given are interacting proteins with association score from different prediction methods, i.e. Neighborhood, Gene Fusion, Co-occurrence, Co-expression, Databases and Textmining.

Additional file 15: Table S13. Biological pathways and their cluster for fused network proteins. REACTOME, KEGG and WikiPathways database information was used as input data file for Cytoscape 3.0.2. The table shows grouping of significant pathway terms $(p \leq 0.01)$ and is based on a kappa score of 0.4 , initial group size of 2 and sharing group percentage of 50 . 
Additional file 16: Table S14. Biological function of newly identified proteins and their previously reported tumour association.

Additional file 17: Table S15. Regulation of genes coding for newly identified proteins in EGF2B-transgenic liver tumours.

Additional file 18: Table S16. Regulation of genes coding for common proteins in tumour tissue and serum of EGF transgenic mice.

\section{Abbreviations}

2DE: 2-D Electrophoresis; ACTH: Adrenocorticotropic hormone; AFP: Alphafetoprotein; AGE: Advanced glycation endproduct; AGTRAP: Angiotensin II, type I receptor-associated protein; AIMP2: Aminoacyl-tRNA synthetases interacting multifunctional protein 2; Alpha-HCCA: Alpha-Cyano-4hydroxycinnamic acid; APS: Ammonium persulfate; ASS: Argininosuccinate synthetase 1; ATP: Adenosine triphosphate; CK: Creatine kinase; CK2A: Casein kinase II subunit alpha; Co: Control specific protein; CPS1: Carbamoyl phosphate synthetase 1; DAB: 3,3'-Diaminobenzidine; DHAP: Dihydroxyacetone phosphate; DR: Down-regulated protein; dr-T: Down-regulated tumour; dr-TrnT: Down-regulated transgenic non-tumour; EGF: Epidermal growth factor; EGFR: Epidermal growth factor receptor; EPS15: Epidermal growth factor receptor substrate 15; EPS15R: Epidermal growth factor receptor substrate 15R; ER: Endoplasmic reticulum; ERK: Extracellular signalling regulated kinase; FDR: False discovery rate; FGFR1: Fibroblast growth factor receptor 1; GDP: Guanosine diphosphate; GNMT: Glycine N-methyltransferase; GO: Gene ontology; GRP170: 170 kDa glucose-regulated protein; GTP: Guanosine triphosphate; $\mathrm{H}_{3} \mathrm{PO}_{4}$ : Orthophosphoric acid; HCA: Hydroxy carboxylic acid; HCC: Hepatocellular carcinoma; HDAC2: Histone deacetylase 2; HED: Bis(2-hydroxyethyl) disulfide; HRP: Horseradish peroxidase; Ig: Immunoglobulin; IHC: Immunohistochemistry; IL-1RA: Interleukin-1 receptor antagonist; KO: Knockout mouse; LB2: Luria-Bertani medium 2; LB3: Luria-Bertani medium 3; MEK: Mitogen-activated protein kinase kinase; NAD: Nicotinamide adenine dinucleotide; $\operatorname{NAD}(P)(H)$ : Nicotinamide adenine dinucleotide phosphate; NADP: Nicotinamide adenine dinucleotide phosphate; NO: Nitric oxide; OGP: n-Octyl $\beta$-D-glucopyranoside; PAl-1: Plasminogen activator inhibitor type-1; PDGFR: Platelet-derived growth factor receptors; PLAUR: Plasminogen activator, urokinase receptor; PMF: Peptide mass fingerprinting; PTBP1: Polypyrimidine tract binding protein 1; RAGE: Receptor for advanced glycation endproduct; S100A1: S100 calcium binding protein A1; SAM: S-adenosylmethionine; shRNA: Short hairpin RNA; STAT5B: Signal transducer and activator of transcription 5B; TEMED: Tetramethylethylenediamine; To: Tumour specific protein; tRNA: Transfer RNA; Tyr845: Tyrosine residue 845; UPA: Urokinase-type plasminogen activator; UR: Up-regulated protein; ur-T: Up-regulated tumour; ur-Tr-nT: Up-regulated transgenic non-tumour; VEGFR: Vascular endothelial growth factor receptor; XBP1(S): X-box binding protein 1 isoform.

\section{Competing interests}

The authors declare that they have no competing interests.

\section{Authors' contributions}

JB conceived the study and contributed the reagents, GG performed the experiments, PS performed the bioinformatics analysis. JB, GG and PS analysed the data, JB wrote the manuscript and all authors read and approved the final manuscript.

\section{Acknowledgements}

We gratefully acknowledge support from The Virtual Liver Network (grant 031 6154) of the German Federal Ministry of Education and Research (BMBF) to JB.

Received: 8 August 2014 Accepted: 3 February 2015

Published online: 25 February 2015

\section{References}

1. Cha C, DeMatteo RP, Blumgart LH. Surgery and ablative therapy for hepatocellular carcinoma. J Clin Gastroenterol. 2002;35:S130-7.

2. Gazzana G, Borlak J. Improved method for proteome mapping of the liver by 2-DE MALDI-TOF MS. J Proteome Res. 2007;6:3143-51.

3. Melle C, Ernst G, Scheibner O, Kaufmann R, Schimmel B, Bleul A, et al. Identification of specific protein markers in microdissected hepatocellular carcinoma. J Proteome Res. 2007;6:306-15.
4. Izzo F, Cremona F, Delrio P, Leonardi E, Castello G, Pignata S, et al. Soluble interleukin-2 receptor levels in hepatocellular cancer: a more sensitive marker than alfa fetoprotein. Ann Surg Oncol. 1999;6:178-85.

5. Wilhelm S, Carter C, Lynch M, Lowinger T, Dumas J, Smith RA, et al. Discovery and development of sorafenib: a multikinase inhibitor for treating cancer. Nat Rev Drug Discov. 2006;5:835-44.

6. Borlak J, Meier T, Halter R, Spanel R, Spanel-Borowski K. Epidermal growth factor-induced hepatocellular carcinoma: gene expression profiles in precursor lesions, early stage and solitary tumours. Oncogene. 2005;24:1809-19.

7. Gazzana G, Borlak J. Mapping of the serum proteome of hepatocellular carcinoma induced by targeted overexpression of epidermal growth factor to liver cells of transgenic mice. J Proteome Res. 2008;7:928-37.

8. Kim HS, Chang YG, Bae HJ, Eun JW, Shen Q, Park SJ, et al. Oncogenic potential of CK2alpha and its regulatory role in EGF-induced HDAC2 expression in human liver cancer. FEBS J. 2014;281:851-61.

9. Fuchs BC, Hoshida Y, Fujii T, Wei L, Yamada S, Lauwers GY, et al. Epidermal growth factor receptor inhibition attenuates liver fibrosis and development of hepatocellular carcinoma. Hepatology. 2014;59:1577-90.

10. Yano S, Kondo K, Yamaguchi M, Richmond G, Hutchison M, Wakeling A, et al. Distribution and function of EGFR in human tissue and the effect of EGFR tyrosine kinase inhibition. Anticancer Res. 2003;23:3639-50.

11. Lin HY, Masso-Welch P, Di YP, Cai JW, Shen JW, Subjeck JR. The 170-kDa glucose-regulated stress protein is an endoplasmic reticulum protein that binds immunoglobulin. Mol Biol Cell. 1993;4:1109-19.

12. Easton DP, Kaneko Y, Subjeck JR. The hsp110 and Grp1 70 stress proteins: newly recognized relatives of the Hsp70s. Cell Stress Chaperones. 2000;5:276-90.

13. Liang RC, Neo JC, Lo SL, Tan GS, Seow TK, Chung MC. Proteome database of hepatocellular carcinoma. J Chromatogr B Analyt Technol Biomed Life Sci. 2002;771:303-28.

14. Blanc JF, Lalanne C, Plomion C, Schmitter JM, Bathany K, Gion JM, et al. Proteomic analysis of differentially expressed proteins in hepatocellular carcinoma developed in patients with chronic viral hepatitis C. Proteomics. 2005;5:3778-89.

15. Sun W, Xing B, Sun Y, Du X, Lu M, Hao C, et al. Proteome analysis of hepatocellular carcinoma by two-dimensional difference gel electrophoresis: novel protein markers in hepatocellular carcinoma tissues. Mol Cell Proteomics. 2007:6:1798-808

16. Yang $M H$, Tyan $Y C$, Jong $S B$, Huang $Y$, Liao $P C$, Wang MC. Identification of human hepatocellular carcinoma-related proteins by proteomic approaches. Anal Bioanal Chem. 2007;388:637-43.

17. Shen H, Cheng G, Fan H, Zhang J, Zhang X, Lu H, et al. Expressed proteome analysis of human hepatocellular carcinoma in nude mice (LCI-D20) with high metastasis potential. Proteomics. 2006;6:528-37.

18. Takashima M, Kuramitsu Y, Yokoyama Y, lizuka N, Fujimoto M, Nishisaka T, et al. Overexpression of alpha enolase in hepatitis $C$ virus-related hepatocellular carcinoma: association with tumor progression as determined by proteomic analysis. Proteomics. 2005;5:1686-92.

19. Wu N, Zhang W, Yang Y, Liang YL, Wang LY, Jin JW, et al. Profilin 1 obtained by proteomic analysis in all-trans retinoic acid-treated hepatocarcinoma cell lines is involved in inhibition of cell proliferation and migration. Proteomics. 2006;:6095-106

20. He QY, Lau GK, Zhou Y, Yuen ST, Lin MC, Kung HF, et al. Serum biomarkers of hepatitis B virus infected liver inflammation: a proteomic study. Proteomics. 2003;3:666-74.

21. Yokoyama Y, Kuramitsu Y, Takashima M, lizuka N, Terai S, Oka M, et al. Protein level of apolipoprotein $\mathrm{E}$ increased in human hepatocellular carcinoma. Int J Oncol. 2006;28:625-31.

22. Ai J, Tan Y, Ying W, Hong Y, Liu S, Wu M, et al. Proteome analysis of hepatocellular carcinoma by laser capture microdissection. Proteomics. 2006;6:538-46.

23. Yokoyama Y, Kuramitsu Y, Takashima M, lizuka N, Toda T, Terai S, et al. Proteomic profiling of proteins decreased in hepatocellular carcinoma from patients infected with hepatitis C virus. Proteomics. 2004;4:2111-6.

24. Kuramitsu Y, Nakamura K. Current progress in proteomic study of hepatitis C virus-related human hepatocellular carcinoma. Expert Rev Proteomics. 2005;2:589-601.

25. Dillon BJ, Prieto VG, Curley SA, Ensor CM, Holtsberg FW, Bomalaski JS, et al. Incidence and distribution of argininosuccinate synthetase deficiency in human cancers: a method for identifying cancers sensitive to arginine deprivation. Cancer. 2004;100:826-33. 
26. Cheng PN, Lam TL, Lam WM, Tsui SM, Cheng AW, Lo WH, et al. Pegylated recombinant human arginase (rhArg-peg5,000 mw) inhibits the in vitro and in vivo proliferation of human hepatocellular carcinoma through arginine depletion. Cancer Res. 2007;67:309-17.

27. Yoon CY, Shim YJ, Kim EH, Lee JH, Won NH, Kim JH, et al. Renal cell carcinoma does not express argininosuccinate synthetase and is highly sensitive to arginine deprivation via arginine deiminase. Int J Cancer. 2007;120:897-905.

28. Svetlov SI, Xiang Y, Oli MW, Foley DP, Huang G, Hayes RL, et al. Identification and preliminary validation of novel biomarkers of acute hepatic ischaemia/ reperfusion injury using dual-platform proteomic/degradomic approaches. Biomarkers. 2006;11:355-69.

29. Feun L, Savaraj N. Pegylated arginine deiminase: a novel anticancer enzyme agent. Expert Opin Investig Drugs. 2006;15:815-22.

30. Wheatley DN, Campbell E. Arginine deprivation, growth inhibition and tumour cell death: 3. Deficient utilisation of citrulline by malignant cells. $\mathrm{Br} J$ Cancer. 2003:89:573-6.

31. Li C, Hong Y, Tan YX, Zhou H, Ai JH, Li SJ, et al. Accurate qualitative and quantitative proteomic analysis of clinical hepatocellular carcinoma using laser capture microdissection coupled with isotope-coded affinity tag and two-dimensional liquid chromatography mass spectrometry. Mol Cell Proteomics. 2004;3:399-409.

32. Capuano F, Varone D, D'Eri N, Russo E, Tommasi S, Montemurro S, et al. Oxidative phosphorylation and F(O)F(1) ATP synthase activity of human hepatocellular carcinoma. Biochem Mol Biol Int. 1996;38:1013-22.

33. Kinoshita M, Miyata M. Underexpression of mRNA in human hepatocellular carcinoma focusing on eight loci. Hepatology. 2002;36:433-8.

34. Xu XR, Huang J, Xu ZG, Qian BZ, Zhu ZD, Yan Q, et al. Insight into hepatocellular carcinogenesis at transcriptome level by comparing gene expression profiles of hepatocellular carcinoma with those of corresponding noncancerous liver. Proc Natl Acad Sci U S A. 2001;98:15089-94.

35. Lim SO, Park SJ, Kim W, Park SG, Kim HJ, Kim Yl, et al. Proteome analysis of hepatocellular carcinoma. Biochem Biophys Res Commun. 2002;291:1031-7.

36. Tada M, Yokosuka O, Fukai K, Chiba T, Imazeki F, Tokuhisa T, et al. Hypermethylation of $\mathrm{NAD}(\mathrm{P}) \mathrm{H}$ : quinone oxidoreductase 1 (NQO1) gene in human hepatocellular carcinoma. J Hepatol. 2005:42:511-9.

37. Amacher DE, Adler R, Herath A, Townsend RR. Use of proteomic methods to identify serum biomarkers associated with rat liver toxicity or hypertrophy. Clin Chem. 2005;51:1796-803.

38. Li L, Chen SH, Yu CH, Li YM, Wang SQ. Identification of hepatocellularcarcinoma-associated antigens and autoantibodies by serological proteome analysis combined with protein microarray. J Proteome Res. 2008;7:611-20.

39. Notarnicola M, Messa C, Cavallini A, Bifulco M, Tecce MF, Eletto D, et al. Higher farnesyl diphosphate synthase activity in human colorectal cancer inhibition of cellular apoptosis. Oncology. 2004;67:351-8.

40. Liang CR, Leow CK, Neo JC, Tan GS, Lo SL, Lim JW, et al. Proteome analysis of human hepatocellular carcinoma tissues by two-dimensional difference gel electrophoresis and mass spectrometry. Proteomics. 2005;5:2258-71.

41. Novoselov SV, Calvisi DF, Labunskyy VM, Factor VM, Carlson BA, Fomenko $D E$, et al. Selenoprotein deficiency and high levels of selenium compounds can effectively inhibit hepatocarcinogenesis in transgenic mice. Oncogene. 2005;24:8003-11.

42. Gladyshev VN, Factor VM, Housseau F, Hatfield DL. Contrasting patterns of regulation of the antioxidant selenoproteins, thioredoxin reductase, and glutathione peroxidase, in cancer cells. Biochem Biophys Res Commun. 1998;251:488-93.

43. Baker RD, Baker SS, LaRosa K, Whitney C, Newburger PE. Selenium regulation of glutathione peroxidase in human hepatoma cell line Hep3B. Arch Biochem Biophys. 1993;304:53-7.

44. Tseng TL, Shih YP, Huang YC, Wang CK, Chen PH, Chang JG, et al. Genotypic and phenotypic characterization of a putative tumor susceptibility gene, GNMT, in liver cancer. Cancer Res. 2003;63:647-54.

45. Liu HH, Chen KH, Shih YP, Lui WY, Wong FH, Chen YM. Characterization of reduced expression of glycine $\mathrm{N}$-methyltransferase in cancerous hepatic tissues using two newly developed monoclonal antibodies. J Biomed Sci. 2003; 10:87-97.

46. Lee $\mathrm{CL}, \mathrm{H}$ siao HH, Lin CW, Wu SP, Huang SY, Wu CY, et al. Strategic shotgun proteomics approach for efficient construction of an expression map of targeted protein families in hepatoma cell lines. Proteomics. 2003;3:2472-86.
47. Zhao Q, Zhao M, Zhang C. The alteration of histidase catalytic activity and the expression of the enzyme protein in rat primary hepatomas]. Zhongguo Yi Xue Ke Xue Yuan Xue Bao. 1994;16:135-9.

48. Liu Y, Zhu X, Zhu J, Liao S, Tang Q, Liu K, et al. Identification of differential expression of genes in hepatocellular carcinoma by suppression subtractive hybridization combined cDNA microarray. Oncol Rep. 2007;18:943-51.

49. Raynes JG, Bevan S. Inhibition of the acute-phase response in a human hepatoma cell line. Agents Actions. 1993;38 Spec No:C66-8.

50. Bevan S, Raynes JG. IL-1 receptor antagonist regulation of acute phase protein synthesis in human hepatoma cells. J Immunol. 1991;147:2574-8.

51. Yamada Y, Karasaki H, Matsushima K, Lee GH, Ogawa K. Expression of an IL-1 receptor antagonist during mouse hepatocarcinogenesis demonstrated by differential display analysis. Lab Invest. 1999;79:1059-67.

52. Dragani TA, Manenti G, Sacchi MR, Colombo BM, Della Porta G. Major urinary protein as a negative tumor marker in mouse hepatocarcinogenesis. Mol Carcinog. 1989;2:355-60.

53. Seow TK, Liang RC, Leow CK, Chung MC. Hepatocellular carcinoma: from bedside to proteomics. Proteomics. 2001;1:1249-63.

54. Schmitz V, Raskopf E, Gonzalez-Carmona MA, Vogt A, Rabe C, Leifeld L, et al. Plasminogen fragment $\mathrm{K} 1-5$ improves survival in a murine hepatocellular carcinoma model. Gut. 2007;56:271-8.

55. Tao KS, Dou KF, Wu XA. Expression of angiostatin cDNA in human hepatocellular carcinoma cell line SMMC-7721 and its effect on implanted carcinoma in nude mice. World J Gastroenterol. 2004;10:1421-4.

56. Kim S, Park HS, Son HJ, Moon WS. The role of angiostatin, vascular endothelial growth factor, matrix metalloproteinase 9 and 12 in the angiogenesis of hepatocellular carcinoma]. Korean J Hepatol. 2004;10:62-72.

57. Looi KS, Nakayasu ES, Diaz RA, Tan EM, Almeida IC, Zhang JY. Using proteomic approach to identify tumor-associated antigens as markers in hepatocellular carcinoma. J Proteome Res. 2008;7:4004-12.

58. Fielden MR, Brennan R, Gollub J. A gene expression biomarker provides early prediction and mechanistic assessment of hepatic tumor induction by nongenotoxic chemicals. Toxicol Sci. 2007:99:90-100.

59. Chan KY, Lai PB, Squire JA, Beheshti B, Wong NL, Sy SM, et al. Positional expression profiling indicates candidate genes in deletion hotspots of hepatocellular carcinoma. Mod Pathol. 2006;19:1546-54.

60. Egawa T, Ito H, Nakamura H, Yamamoto H, Kishimoto S. Hormonal regulation of vitamin D-binding protein production by a human hepatoma cell line. Biochem Int. 1992;28:551-7.

61. Rzhetsky A, lossifov I, Koike T, Krauthammer M, Kra P, Morris M, et al. GeneWays: a system for extracting, analyzing, visualizing, and integrating molecular pathway data. J Biomed Inform. 2004;37:43-53.

62. Lazarevich NL, Cheremnova OA, Varga EV, Ovchinnikov DA, Kudrjavtseva El, Morozova OV, et al. Progression of HCC in mice is associated with a downregulation in the expression of hepatocyte nuclear factors. Hepatology. 2004;39:1038-47.

63. Bronte V, Kasic T, Gri G, Gallana K, Borsellino G, Marigo I, et al. Boosting antitumor responses of $\mathrm{T}$ lymphocytes infiltrating human prostate cancers. J Exp Med. 2005:201:1257-68.

64. Yamada M, Ichikawa Y, Yamagishi S, Momiyama N, Ota M, Fujii S, et al. Amphiregulin is a promising prognostic marker for liver metastases of colorectal cancer. Clin Cancer Res. 2008;14:2351-6.

65. Zhang T, Huang XH, Dong L, Hu D, Ge C, Zhan YQ, et al. PCBP-1 regulates alternative splicing of the CD44 gene and inhibits invasion in human hepatoma cell line HepG2 cells. Mol Cancer. 2010;9:72-4598-9-72.

66. Niehof M, Borlak J. EPS15R, TASP1, and PRPF3 are novel disease candidate genes targeted by HNF4alpha splice variants in hepatocellular carcinomas. Gastroenterology. 2008;134:1191-202.

67. Steel LF, Shumpert D, Trotter M, Seeholzer SH, Evans AA, London WT, et al. A strategy for the comparative analysis of serum proteomes for the discovery of biomarkers for hepatocellular carcinoma. Proteomics. 2003;3:601-9.

68. Kawakami T, Hoshida Y, Kanai F, Tanaka Y, Tateishi K, Ikenoue T, et al. Proteomic analysis of sera from hepatocellular carcinoma patients after radiofrequency ablation treatment. Proteomics. 2005;5:4287-95.

69. Chignard N, Beretta L. Proteomics for hepatocellular carcinoma marker discovery. Gastroenterology. 2004;127:S120-5.

70. Ko KS, Tomasi ML, Iglesias-Ara A, French BA, French SW, Ramani K, et al. Liver-specific deletion of prohibitin 1 results in spontaneous liver injury, fibrosis, and hepatocellular carcinoma in mice. Hepatology. 2010;52:2096-108.

71. Kobayashi E, Masuda M, Nakayama R, Ichikawa H, Satow R, Shitashige M, et al. Reduced argininosuccinate synthetase is a predictive biomarker for 
the development of pulmonary metastasis in patients with osteosarcoma. Mol Cancer Ther. 2010;9:535-44.

72. Velichkova P, Himo F. Methyl transfer in glycine N-methyltransferase. A theoretical study. J Phys Chem B. 2005;109:8216-9.

73. DebRoy S, Kramarenko II, Ghose S, Oleinik NV, Krupenko SA, Krupenko NI. A novel tumor suppressor function of glycine $\mathrm{N}$-methyltransferase is independent of its catalytic activity but requires nuclear localization. PLoS One. 2013;8:e70062.

74. Liu AM, Xu Z, Shek FH, Wong KF, Lee NP, Poon RT, et al. miR-122 targets pyruvate kinase $\mathrm{M} 2$ and affects metabolism of hepatocellular carcinoma. PLoS One. 2014;9:e86872.

75. Royds JA, Kennedy HJ, Little PV, Taylor CB, Triger DR. Serum aldolase isoenzymes in benign and malignant liver disease. Clin Chim Acta. 1987;167:237-46.

76. Park SG, Schimmel P, Kim S. Aminoacyl tRNA synthetases and their connections to disease. Proc Natl Acad Sci U S A. 2008;105:11043-9.

77. Chang SH, Chung YS, Hwang SK, Kwon JT, Minai-Tehrani A, Kim S, et al. Lentiviral vector-mediated shRNA against AIMP2-DX2 suppresses lung cancer cell growth through blocking glucose uptake. Mol Cells. 2012;33:553-62.

78. Chung YT, Matkowskyj KA, Li H, Bai H, Zhang W, Tsao MS, et al. Overexpression and oncogenic function of aldo-keto reductase family 1B10 (AKR1B10) in pancreatic carcinoma. Mod Pathol. 2012;25:758-66.

79. Yan R, Zu X, Ma J, Liu Z, Adeyanju M, Cao D. Aldo-keto reductase family 1 B10 gene silencing results in growth inhibition of colorectal cancer cells: Implication for cancer intervention. Int J Cancer. 2007;121:2301-6.

80. Zhang J, Song M, Wang J, Sun M, Wang B, Li R, et al. Enoyl coenzyme A hydratase 1 is an important factor in the lymphatic metastasis of tumors. Biomed Pharmacother. 2011;65:157-62.

81. Hung JJ, Chow KC, Wang HW, Wang LS. Expression of dihydrodiol dehydrogenase and resistance to chemotherapy and radiotherapy in adenocarcinoma cells of lung. Anticancer Res. 2006;26:2949-55.

82. Andriamihaja M, Chaumontet C, Tome D, Blachier F. Butyrate metabolism in human colon carcinoma cells: implications concerning its growth-inhibitory effect. J Cell Physiol. 2009;218:58-65.

83. Donohoe DR, Collins LB, Wali A, Bigler R, Sun W, Bultman SJ. The Warburg effect dictates the mechanism of butyrate-mediated histone acetylation and cell proliferation. Mol Cell. 2012;48:612-26.

84. Ahmed K. Biological roles and therapeutic potential of hydroxy-carboxylic Acid receptors. Front Endocrin. 2011;2:51.

85. Umezu-Goto M, Kishi Y, Taira A, Hama K, Dohmae N, Takio K, et al. Autotaxin has lysophospholipase D activity leading to tumor cell growth and motility by lysophosphatidic acid production. J Cell Biol. 2002;158:227-33.

86. Dhar MK, Koul A, Kaul S. Farnesyl pyrophosphate synthase: a key enzyme in isoprenoid biosynthetic pathway and potential molecular target for drug development. N Biotechnol. 2013;30:114-23.

87. Deng S, Zhou H, Xiong R, Lu Y, Yan D, Xing T, et al. Over-expression of genes and proteins of ubiquitin specific peptidases (USPs) and proteasome subunits (PSs) in breast cancer tissue observed by the methods of RFDD-PCR and proteomics. Breast Cancer Res Treat. 2007;104:21-30.

88. Rotondo R, Mastracci L, Piazza T, Barisione G, Fabbi M, Cassanello M, et al. Arginase 2 is expressed by human lung cancer, but it neither induces immune suppression, nor affects disease progression. Int J Cancer. 2008;123:1108-16.

89. Grunewald TG, Kammerer U, Kapp M, Eck M, Dietl J, Butt E, et al. Nuclear localization and cytosolic overexpression of LASP-1 correlates with tumor size and nodal-positivity of human breast carcinoma. BMC Cancer. 2007;7:198.

90. Lin YH, Park ZY, Lin D, Brahmbhatt AA, Rio MC, Yates III JR, et al. Regulation of cell migration and survival by focal adhesion targeting of Lasp-1. J Cell Biol. 2004;165:421-32.

91. Zhao P, Hou L, Farley K, Sundrud MS, Remold-O'Donnell E. SerpinB1 regulates homeostatic expansion of $\mathrm{IL}-17+$ gammadelta and CD4+ Th17 cells. J Leukoc Biol. 2014;95:521-30.

92. Zhou Y, Xu Y, Tan Y, Qi J, Xiao Y, Yang C, et al. Sorcin, an important gene associated with multidrug-resistance in human leukemia cells. Leuk Res. 2006;30:469-76.

93. Chen Y, Lin P, Qiu S, Peng XX, Looi K, Farquhar MG, et al. Autoantibodies to $\mathrm{Ca} 2+$ binding protein Calnuc is a potential marker in colon cancer detection. Int J Oncol. 2007;30:1137-44.

94. Giusti L, lacconi P, Ciregia F, Giannaccini G, Donatini GL, Basolo F, et al. Fine-needle aspiration of thyroid nodules: proteomic analysis to identify cancer biomarkers. J Proteome Res. 2008;7:4079-88.
95. Akagi T, Murata K, Shishido T, Hanafusa H. v-Crk activates the phosphoinositide 3-kinase/AKT pathway by utilizing focal adhesion kinase and H-Ras. Mol Cell Biol. 2002;22:7015-23.

96. Simpson-Haidaris PJ, Rybarczyk B. Tumors and fibrinogen. The role of fibrinogen as an extracellular matrix protein. Ann N Y Acad Sci. 2001;936:406-25.

97. Palumbo JS, Kombrinck KW, Drew AF, Grimes TS, Kiser JH, Degen JL, et al. Fibrinogen is an important determinant of the metastatic potential of circulating tumor cells. Blood. 2000;96:3302-9.

98. Godier A, Hunt BJ. Plasminogen receptors and their role in the pathogenesis of inflammatory, autoimmune and malignant disease. J Thromb Haemost. 2013;11:26-34.

99. Jo M, Thomas KS, Takimoto S, Gaultier A, Hsieh EH, Lester RD, et al. Urokinase receptor primes cells to proliferate in response to epidermal growth factor. Oncogene. 2007;26:2585-94.

100. Zheng Q, Tang ZY, Xue Q, Shi DR, Song HY, Tang HB. Invasion and metastasis of hepatocellular carcinoma in relation to urokinase-type plasminogen activator, its receptor and inhibitor. J Cancer Res Clin Oncol. 2000;126:641-6.

101. Huch M, Gros A, Jose A, Gonzalez JR, Alemany R, Fillat C. Urokinase-type plasminogen activator receptor transcriptionally controlled adenoviruses eradicate pancreatic tumors and liver metastasis in mouse models. Neoplasia. 2009;11:518-28.

102. Halamkova J, Kiss I, Tomasek J, Pavlovsky Z, Cech Z, Tutek S, et al. Plasminogen activator system and its clinical significance in patients with a malignant disease. Klin Onkol. 2011;24:418-23.

103. Duffy MJ. The urokinase plasminogen activator system: role in malignancy. Curr Pharm Des. 2004;10:39-49.

104. Bechmann LP, Hannivoort RA, Gerken G, Hotamisligil GS, Trauner M, Canbay A. The interaction of hepatic lipid and glucose metabolism in liver diseases. J Hepatol. 2012;56:952-64.

105. Chen YC, Pohl G, Wang TL, Morin PJ, Risberg B, Kristensen GB, et al. Apolipoprotein $\mathrm{E}$ is required for cell proliferation and survival in ovarian cancer. Cancer Res. 2005;65:331-7.

106. Yang L, Zhang J, Zhang S, Dong W, Lou X, Liu S. Quantitative evaluation of aldo-keto reductase expression in hepatocellular carcinoma (HCC) cell lines. Genomics Proteomics Bioinformatics. 2013;11:230-40.

107. Tajima M, Kurashima Y, Sugiyama K, Ogura T, Sakagami H. The redox state of glutathione regulates the hypoxic induction of HIF-1. Eur J Pharmacol. 2009;606:45-9.

108. Rhee SG, Yang KS, Kang SW, Woo HA, Chang TS. Controlled elimination of intracellular $\mathrm{H}(2) \mathrm{O}(2)$ : regulation of peroxiredoxin, catalase, and glutathione peroxidase via post-translational modification. Antioxid Redox Signal. 2005;7:619-26

109. DiNorcia J, Moroziewicz DN, Ippagunta N, Lee MK, Foster M, Rotterdam HZ, et al. RAGE signaling significantly impacts tumorigenesis and hepatic tumor growth in murine models of colorectal carcinoma. J Gastrointest Surg. 2010;14:1680-90.

110. Leclerc E, Fritz G, Vetter SW, Heizmann CW. Binding of S100 proteins to RAGE: an update. Biochim Biophys Acta. 2009;1793:993-1007.

111. Logsdon CD, Fuentes MK, Huang EH, Arumugam T. RAGE and RAGE ligands in cancer. Curr Mol Med. 2007;7:777-89.

112. Vlassara H, Li YM, Imani F, Wojciechowicz D, Yang Z, Liu FT, et al. Identification of galectin-3 as a high-affinity binding protein for advanced glycation end products (AGE): a new member of the AGE-receptor complex. Mol Med. 1995;1:634-46.

113. Klingelhofer J, Moller HD, Sumer EU, Berg CH, Poulsen M, Kiryushko D, et al. Epidermal growth factor receptor ligands as new extracellular targets for the metastasis-promoting S100A4 protein. FEBS J. 2009;276:5936-48.

114. Yin C, Li H, Zhang B, Liu Y, Lu G, Lu S, et al. RAGE-binding S100A8/A9 promotes the migration and invasion of human breast cancer cells through actin polymerization and epithelial-mesenchymal transition. Breast Cancer Res Treat. 2013;142:297-309.

115. Cai W, He JC, Zhu L, Lu C, Vlassara H. Advanced glycation end product (AGE) receptor 1 suppresses cell oxidant stress and activation signaling via EGF receptor. Proc Natl Acad Sci U S A. 2006;103:13801-6.

116. Huang YW, Jansen RA, Fabbri E, Potter D, Liyanarachchi S, Chan MW, et al. Identification of candidate epigenetic biomarkers for ovarian cancer detection. Oncol Rep. 2009;22:853-61.

117. Locasale JW, Grassian AR, Melman T, Lyssiotis CA, Mattaini KR, Bass AJ, et al. Phosphoglycerate dehydrogenase diverts glycolytic flux and contributes to oncogenesis. Nat Genet. 2011;43:869-74. 
118. Wallimann T, Wyss M, Brdiczka D, Nicolay K, Eppenberger HM. Intracellular compartmentation, structure and function of creatine kinase isoenzymes in tissues with high and fluctuating energy demands: the'phosphocreatine circuit' for cellular energy homeostasis. Biochem J. 1992;281(Pt 1):21-40.

119. Wyss M, Kaddurah-Daouk R. Creatine and creatinine metabolism. Physiol Rev. 2000:80:1107-213.

120. Kanemitsu F, Kawanishi I, Mizushima J, Okigaki T. Mitochondrial creatine kinase as a tumor-associated marker. Clin Chim Acta. 1984:138:175-83.

121. Meffert G, Gellerich FN, Margreiter R, Wyss M. Elevated creatine kinase activity in primary hepatocellular carcinoma. BMC Gastroenterol. 2005;5:9.

122. Battaglia V, Rossi CA, Colombatto S, Grillo MA, Toninello A. Different behavior of agmatine in liver mitochondria: inducer of oxidative stress or scavenger of reactive oxygen species? Biochim Biophys Acta. 2007;1768:1147-53

123. Masson N, Ratcliffe PJ. Hypoxia signaling pathways in cancer metabolism: the importance of co-selecting interconnected physiological pathways. Cancer Metab. 2014;2:3-3002-2-3.

124. Feun L, You M, Wu CJ, Kuo MT, Wangpaichitr M, Spector S, et al. Arginine deprivation as a targeted therapy for cancer. Curr Pharm Des. 2008;14:1049-57.

125. Liu H, Dong H, Robertson K, Liu C. DNA methylation suppresses expression of the urea cycle enzyme carbamoyl phosphate synthetase 1 (CPS1) in human hepatocellular carcinoma. Am J Pathol. 2011;178:652-61.

\section{Submit your next manuscript to BioMed Central and take full advantage of:}

- Convenient online submission

- Thorough peer review

- No space constraints or color figure charges

- Immediate publication on acceptance

- Inclusion in PubMed, CAS, Scopus and Google Scholar

- Research which is freely available for redistribution 